\title{
AUTORÍA MEDIATA, IMPUTACIÓN OBJETIVA Y AUTOPUESTAS EN PELIGRO $^{1}$
}

\author{
A PROPÓSITO DE LA STS 26-2-2000 (A 1149), M. P: \\ ENRIQUE BACIGALUPO ZAPATER
}

Raquel Roso Cañadillas

\section{RESUMEN DE LOS HECHOS Y FUNDAMENTOS DE DERECHO}

El supuesto de hecho de la sentencia objeto de este comentario es el siguiente:

El pasado día 14 de marzo de 1997 Iván D. S., que contaba en dichas fechas con 16 años de edad, se encontraba haciendo auto-stop en las inmediaciones del surtidor de gasolina conocido por 'Ventosilla' en la ciudad de Trebujena, en la carretera C-411. Al pasar por el lugar JoAquín C. S., conduciendo un Renault Express, matrícula SE-É-AT, se detuvo ofreciéndose a llevarlo. Una

1. Índice de abreviaturas: $A D P C P$ : Anuario de Derecho Penal y Ciencias Penales (revista, cit. por año); AFDUA: Anuario de la Facultad de Derecho de la Universidad de Alcalá (revista, cit. por año); APen: Actualidad Penal (revista, cit. por año); AT: Allgemeiner Teil; ComLP: Comentarios a la Legislación Penal, Cobo Del Rosal (dir.), varios temas, Madrid, Edersa; DPCir, Derecho Penal de la Circulación; EPBCom: Enciclopedia Penal Básica, Diego-Manuel Luzón Peña (dir.), Granada, Edit. Comares, 2002; EPen: Estudios Penales; GA: Goltdammer's Archiv für Strafrecht (revista, cit. por año); LL: La Ley (revista cit. por tomo y año); LK: Leipziger Kommentar, Berlin, De Gruyter (comentarios al C. P. alemán); L-H: Libro-Homenaje; NJW: Neue Juristische Wochenschrift (revista cit. por año); RDCir: Revista de Derecho de la Circulación (cit. por año); RDPCr: Revista de Derecho penal y criminología (cit. por tomo y año); RDPP: Revista Derecho y Proceso Penal, Aranzadi (cit. por tomo y año); RoxinFS: Festschrift für Claus Roxin, Berlin, de Gruyter, 2002; SK: Systematischer Kommentar zum StGB (comentarios al C. P. alemán); TSJ y AP Aranzadi: Tribunales Superiores de Justicia y Audiencias Provinciales de Aranzadi (revista, cit. por número y año); TuT: Täterschaft und Tatherrschaft. 
vez en el vehículo, e iniciada la marcha, JoAQuín comenzó a pedirle a IvÁN dinero, manifestándole éste que no tenía. Posteriormente le requirió para que le enseñara el reloj que llevaba, diciéndole que se lo entregara en su mano, a lo que IVÁN se negó; insistiendo JOAQUín en sus pretensiones diciéndole que tenía una navaja. IvÁN, asustado, pidió a JOAQUín que parara el vehículo para bajarse, a lo que aquél se negó, pese a la insistencia de Iván, el cual nervioso insistía en que parara o se tiraba del vehículo, haciendo incluso ademán de abrir la puerta. Ante la insistencia de IvÁn, JOAQuín se negó a parar el vehículo diciéndole que se tirara si quería, ante lo cual Iván abrió la puerta saltando del vehículo en marcha. Como consecuencia de la caída que sufrió al saltar del vehículo, IvÁn sufrió lesiones de las que tardó en obtener la sanidad 45 días, 30 de ellos impedido para sus ocupaciones y precisando tratamiento médico para su curación, obteniendo la sanidad quedándole como secuelas una cicatriz en el hombro derecho de 8 x $4 \mathrm{~cm}$. y otra en el codo izquierdo de $2 \mathrm{~cm}$. de diámetro. JoAquín, tras tirarse IvÁN del vehículo, siguió su marcha, sin detenerse.

La Audiencia de Cádiz condenó al acusado JoAquín C. S. como autor de un delito de robo con intimidación en grado de tentativa y de un delito de lesiones. El acusado recurrió en casación ante el Tribunal Supremo que declaró haber lugar parcialmente al recurso, dictando segunda sentencia en la que absuelve a JoAquín C. S. del delito de lesiones y mantiene la condena por la tentativa de robo. El Tribunal Supremo considera que en el caso descrito el problema se plantea en el ámbito de la imputación objetiva y por tanto "se trata de si las lesiones producidas por el comportamiento autodefensivo de la víctima de un robo pueden ser imputadas al autor de la violencia o intimidación". "El punto de partida de la verificación de la imputación objetiva es claro: el resultado se debe imputar al autor siempre y cuando sea la realización de un peligro jurídicamente desaprobado, creado por su acción"2.

Un caso parecido se planteó a esta misma Sala a principios de los $90^{3}$. En esta ocasión era una joven que también hacía auto-stop y fue recogida por el conductor de un camión, que durante el trayecto le hizo insistentemente proposiciones sexuales. Esa insistencia provocó un estado de nerviosismo y pánico en la muchacha, la cual solicitaba al conductor que parara el vehículo, haciendo el procesado caso omiso de sus ruegos. Ante tal situación la joven perdió el control y se arrojó del camión, resultando lesionada al ser alcanzado su miembro inferior izquierdo por las ruedas del vehículo. En esta sentencia [8-11-1991, A 8298 (Pte. Delgado García)], al contrario que en la anterior, el Tribunal Supremo condena al conductor del camión como autor de un delito de imprudencia temeraria basándose en que hubo imprudencia con resultado de lesiones, en que pudo prever la reacción de la joven, y en que además “el procesado era dueño de la situación $n^{4}$ y pudo evitar que la joven llegara a realizar tan peligro-

2. Fundamento de derecho cuarto.

3. Cfr. Roso CAÑadillas. Autoría y participación en el delito imprudente, Granada, Edit. Comares, 2002, pp. 474 y 475.

4. Sin cursiva en el original. 
sa acción, simplemente cesando en sus proposiciones deshonestas o parando el vehículo para que ella se bajara". Por todo ello, la sentencia afirma "que la única causa de las lesiones sufridas por MERCEDES se encuentra en el comportamiento claramente reprochable de JEsús M. S., pues fue su conducta ilegítima de agresión a la joven la que provocó la actuación ilegítima de ésta de arrojarse del camión en marcha. El conductor del vehículo con su comportamiento creó un riesgo, del que la propia ofendida le advirtió cuando le dijo que se tiraría si no paraba, y en el ámbito de ese riesgo producido y advertido por él se produjo ese acto voluntario de ella (voluntario pese a encontrarse con sus facultades cognoscitivas y volitivas disminuidas por la tensión nerviosa que sufría), que fue el origen del posterior atropello de su propio cuerpo con las ruedas traseras del mismo camión. Tal conducta voluntaria de MERCEDEs, al haberse realizado dentro del ámbito de riesgo creado por el acusado, no interrumpió el nexo causal entre el anterior comportamiento de JEsús y las posteriores lesiones de aquélla, que, por tanto, son objetivamente imputables a JEsús M. S.”.

En los dos "supuestos del auto-stop"5 la afirmación o negación de la responsabilidad penal por las lesiones se fundamenta en la existencia o no de la imputación objetiva -por

5. Otros casos relativamente recientes en nuestra jurisprudencia, que, pese a que no son siquiera parecidos sus supuestos de hecho, sin embargo, atendiendo a las cuestiones de fondo, plantean la misma problemática, son los siguientes: STS 27-1-1984, A 421 (Pte. Latour), en la que se describe el siguiente supuesto de hecho: cuatro personas pasean por una zona peatonal, a distinto nivel de la calzada reservada a vehículos. Por la calzada se aproxima un conductor que había obtenido hacía poco su permiso de conducir y lo hace de modo tan inexperto que invade la zona peatonal, causando la muerte de inmediato a uno de los peatones que formaba el grupo de cuatro, tras esquivar los otros el atropello. En ese momento uno de ellos, "Victoria H., por lo ocurrido y viendo el cuerpo tendido de SanTiago M., salió corriendo presa de pánico y llamando a la esposa de éste que se acababa de separar del grupo, yendo a precipitarse bajo las ruedas de otro vehículo que circulaba en sentido contrario al que lo hizo el procesado y que la atropelló sin que su conductor pudiera hacer nada para evitarlo". El Tribunal Supremo condena como autor al conductor inexperto por muerte y lesiones, basándose en el elemento sistemático de la causalidad jurídica, categoría de elaboración plenamente jurisprudencial y acreedora de múltiples críticas, ya que encierra en ella caracteres axiológicos y normativos, que no son propios de la causalidad y que se acercan en muchos casos a los criterios integrantes de la imputación objetiva. Con base, por tanto, en la causalidad jurídica, el Tribunal Supremo afirma que también se le pueden imputar las lesiones de VICTORIA al inexperto conductor, puesto que "la ciega carrera de Victoria vino motivada por la inicial acción temeraria del conductor y procesado, creador de la situación de peligro, que provocó el estado anímico de terror y espanto y que fue el factor de que no adoptase precauciones en su loco afán de alejarse del lugar donde a punto estuvo de perder la vida y con la finalidad de avisar a su amiga del trágico fin de su esposo, con lo que la actuación del segundo automóvil no supone más que una causalidad material dentro de la específicamente jurídica que se ha estudiado". Cfr. respecto de esta sentencia los comentarios y análisis jurisprudencial de SiLvA. "Límites en la responsabilidad por imprudencia", en $L L$ 1984-4, pp. 1041 y ss.; LuZÓn PEÑA. "Autoría e imputación objetiva en el delito imprudente”, en RDCir 1984, pp. 275 y ss.; DPCir, 2. ․ ed., 1990, pp. 83 y ss.; Roso Cañadillas. Autoría, 2002, pp. 471 y ss. La STS 30-12-1996, A 9244 (Pte. MartíneZPereda Rodríguez) se ocupa del supuesto en el que una esposa, muy asustada por los maltratos de obra y las amenazas de matarla que recibía de su marido, al desasirse de éste, que la mantenía con una mano agarrada por la muñeca y con la otra por el cuello, corre al balcón y se tira a la calle produciéndose varias lesiones. La Audencia de Palma de Mallorca condena al marido como autor de un delito de lesiones. El Tribunal Supremo le absuelve de este delito, ya que faltaba la imputación objetiva, puesto que "si bien puede predicarse una causalidad material, no puede sostenerse la moral, pues falta la 
lo que se dejan aparte otras posibles cuestiones que en la sentencia de 1991 quedan simplemente apuntadas ${ }^{6}$-, y sin embargo los fallos son diametralmente opuestos. Estas diferencias en la solución la explica el ponente ${ }^{7}$ de la última sentencia y sostiene que, pese a la similitud en los hechos de ambas sentencias, en estos supuestos tiene una importancia decisiva la configuración del hecho. "En este sentido parece claro que no todas las acciones de autoprotección, consistentes en arrojarse de un vehículo en marcha para eludir una agresión, deben tener la misma significación. Sin duda que de todas ellas habrá que afirmar la causalidad en el sentido de la conditio sine qua non, pues si la víctima no se hubiera encontrado en la situación creada por el autor no se hubiera arrojado del coche. Pero, no toda causalidad es relevante. En los casos en que la víctima opta por crear con su acción un peligro mucho mayor que el realmente generado por el autor, sin una justificación especial, los resultados que sean producto de la introducción de este nuevo peligro más grave no deben ser imputados a dicho autor ${ }^{8}$. En la ponderación de la diferencia entre el peligro corrido y el peligro asumido tiene singular relevancia la diferencia jerárquica de los bienes jurídicos afectados y la configuración real de la situación en la que el agredido se encuentra"”.

\section{SOLUCIONES DOCTRINALES}

Esta sentencia, que apenas tiene dos años de vida, ha sido objeto ya de numerosos comentarios científicos, la mayoría de ellos realizados por monografistas cuyas investigaciones se han centrado en el análisis de la conducta de la víctima y las posibles consecuencias y repercusiones de su comportamiento en el ordenamiento penal. Por

imputación objetiva, porque el resultado acaecido quedó fuera del ámbito de protección de la norma que el autor ha vulnerado mediante su acción, ya que en este caso no se realiza en el resultado el riesgo jurídicamente desaprobado que ha creado el autor, sino otra clase de riesgo, diferente y extraño a aquél”. Cfr. Roso. Autoría, 2002, p. 475. STS 17-9-1999, A 6667, (Pte. Bacigalupo Zapater): "Sobre las 14 horas del día 11 de agosto de 1997 cuando se encontraban el acusado FEDERICo R. T. y FrancisCo Manuel H. C. junto con otros en la avenida de Andalucía de Nueva Carteya, tuvo lugar una discusión entre ambos, que posteriormente derivó en una pelea al propinarle FrANCISCO MANUEL un tortazo a FEDERICO, como consecuencia de un comentario que había efectuado, tirándolo al suelo; éste se levantó y cogió una silla de plástico de la terraza, momento en que también la asió FRANCISCO MANUEL, llevando a cabo un forcejeo entre los dos, cayendo este último al suelo a causa del fragor de la pelea, y sufriendo como consecuencia de la caída una fractura subcapital del hombro derecho, necesitando por ello tratamiento médico y quirúrgico". El Tribunal Supremo estimó parcialmente el recurso interpuesto por el acusado y consideró que no debían imputársele objetivamente las lesiones a FEDERICO, debido a que el perjudicado era consciente del peligro que asumía y hubo una decisión voluntaria en su actuación. Cfr. los comentarios doctrinales realizados a esta sentencia por Feıóo. "Actuación de la víctima e imputación objetiva" (comentario a la STS del 17 de septiembre de 1999), en $R D P C r 5$ (2000), pp. 265 a 333 y por González Cussac y Mira Benavent. "Ámbito de responsabilidad de la víctima y teoría de la imputación objetiva”, en Díez Ripollés, Romeo Casabona, Gracia Martín e Higuera Guimerá (eds.). La ciencia del Derecho Penal ante el nuevo siglo, L-H a Cerezo Mir, Madrid, Edit. Tecnos, 2002.

6. Así cuando se dice que el procesado era el único "dueño de la situación" o que "fue su conducta ilegítima de agresión a la joven la que provocó la actuación ilegítima de ésta de arrojarse”.

7. EnRiQue BACIGALUPo ZAPATER.

8. Sin cursiva en el original.

9. Fundamento de derecho cuarto. 
ello, y estableciendo un orden de análisis ${ }^{10}$, es más obligada, si cabe, la exposición de las tesis que han defendido estos autores para solucionar el supuesto de hecho planteado por la sentencia, y como, adelanto, las posiciones son muy distintas, será inevitable realizar una comparación argumentativa, que en cualquier caso contribuye a la discusión científica, mejorando planteamientos y soluciones. Por otro lado, ello también pone de relieve, ante la numerosa respuesta científica en estos casos, la importancia que va adquiriendo 'la víctima' dentro del Derecho Penal. Ha pasado de ser un mero sujeto pasivo a ser considerada, según los casos, un interviniente más, aunque 'cualificado', ya que su participación en el hecho conlleva, si cumple una serie de requisitos, la extinción -y en el peor de los casos la atenuación- de la responsabilidad penal de los demás intervinientes en el hecho ${ }^{11}$.

\section{A. LA SOLUCIÓN DE MAYOL}

MAYOL ha denominado este grupo de casos acciones defensivas de carácter autolesivo ${ }^{12}$, y encuentra su problema fundamental en la imputación del resultado lesivo ya sea a la propia víctima, ya sea al autor. Ello le conduce inevitablemente a ubicar el tema en el tipo objetivo y a centrar su análisis en la imputación objetiva; pero debido a la peculiaridad que presenta dicho grupo de casos, en el que se debe tener en cuenta la conducta de la víctima y su "participación” en el hecho, sostiene que la solución se debe buscar interpretando las categorías del tipo objetivo -y aquí se encuentra el punto sustancial y básico de su tesis- desde los principios que rigen la legítima defensa. Desde este punto de partida, MAYOL mantiene que, si el agresor en la legítima defensa tiene el deber de tolerar la acción de salvaguarda del sujeto agredido, y a éste se le justifica esta conducta siempre que se mantenga dentro de los límites de la causa de justificación, se puede concluir, mutatis mutandis, "que en los casos en los que el agredido (víctima) reacciona a un ataque imputable plenamente al agresor mediante una acción de salvaguarda que recae sobre él mismo, tenga que ser el agresor, en principio, quien responda de las consecuencias lesivas que se deriven. Ello será así cuando la reacción de la víctima, de haber recaído frente al agresor, hubiese entrado dentro de los límites de lo permitido por la eximente de legítima defensa"13. Por tanto, MAYOL parte de la base de que estos supuestos guardan una gran similitud en su

10. Se ha elegido el orden cronológico de aparición de las publicaciones, para desarrollar la exposición en el texto de las distintas tesis de los autores; y, en el caso en el que han aparecido en la misma publicación, se ha respetado el propio orden interno de exposición del artículo.

11. Ahora bien, como en toda regla también hay excepciones, y así seguirá existiendo responsabilidad del tercero que actúa junto a la víctima, pese a que haya consentimiento originado por una decisión libre y voluntaria por parte de ésta o una organización conjunta del hecho con un ámbito preferente de responsabilidad para la víctima, cuando se trate del favorecimiento de un suicidio o de un homicidio a petición. Cfr. artículo 143 C. $\mathrm{P}$.

12. Mayol. "Acciones defensivas de carácter autolesivo derivadas de un peligro generado por el autor" (comentario a la STS del 26 de febrero de 2000), en APen 2001, p. 47, las define como "acciones defensivas llevadas a cabo por la propia víctima y que recaen sobre legítimos intereses de ella, cuando derivan de una situación de peligro creada por el autor".

13. APen 2001, p. 49. 
estructura con los de la legítima defensa, ya que aquí también hay un agredido, un agresor y una conducta defensiva ante un ataque ilegítimo del agresor. La diferencia, aunque fundamental, sólo está en que las acciones defensivas de carácter autolesivo son atípicas, y por tanto no hay necesidad de justificar el tipo penal realizado por el agredido; pero ello sólo sirve para volver a situar, pese a la aplicación analógica de las reglas de la legítima defensa, la discusión en el tipo objetivo. Sentada la tesis de partida, MAYOL desarrolla, para fundamentar su postura, dos cuestiones: en primer lugar, la determinación de la relación de autoría y, en segundo lugar, los límites de la responsabilidad del autor.

Para determinar la relación de autoría, MAYOL vuelve a recurrir al ámbito de la justificación y mantiene, desde esta perspectiva, que la estructura que presentan los supuestos de acciones defensivas de carácter autolesivo es idéntica a la de las situaciones de "defensa que recaen sobre un tercero"14, lo único que las diferencia es la persona objeto de la acción de defensa: en el primer caso, sería la propia víctima-agredida; en el segundo caso, sería un tercero completamente ajeno a la situación de peligro creada por el agresor ${ }^{15}$. Este obstáculo para MAYOL no presenta la entidad suficiente como para no poder sostener la misma solución dogmática en ambos casos por lo que respecta al tratamiento jurídico del agresor en cuanto a la cuestión de la autoría. Así, si en los supuestos de "defensa que recaen en un tercero" es posible afirmar la autoría mediata del agresor que coloca al agredido en un estado de necesidad agresivo lesionando bienes de terceros, basada en el concepto de dominio de la voluntad, ya que "con su conducta coloca al agredido en una situación tal que le obliga a elegir entre soportar el peligro amenazante o emprender una acción de defensa que crea un nuevo riesgo para intereses legítimos de terceros" 16 , de igual modo considera que se puede afirmar la autoría mediata en los "supuestos en que el agresor coloca a la víctima (agredido) en una situación en la que le obliga a elegir entre soportar el peligro amenazante o emprender una acción defensiva autolesiva"17.

Pasando a la segunda cuestión, y como ya he adelantado, MAYOL analiza la imputación objetiva en los supuestos de acciones defensivas de carácter autolesivo desde los requisitos y límites de la legítima defensa. En consecuencia, si se dan todos los requisitos objetivos y subjetivo de la causa de justificación, habrá imputación objetiva y el resultado será creación del riesgo originado por el agresor con su acción; y si, por el contrario, falta alguno de estos requisitos, no se le podrá imputar el resultado al agresor, aunque ello no implicará directamente la impunidad, sino que las soluciones

14. Mayol, en APen 2001, p. 50, se refiere con esta denominación a una situación en la que "el ejercicio de la facultad de defensa frente al sujeto plenamente competente del peligro es inviable o supone una relevante minoración de las posibilidades de salvación, en cuyo caso el emprendimiento de una acción de salvaguarda lesiva de intereses de sujetos ajenos a la situación de coacción aparece como único recurso".

15. Ibíd., p. 53.

16. Ídem.

17. Ídem. 
y, por ende, la responsabilidad penal, como expone MAYOL, serán diversas dependiendo del requisito de la legítima defensa que falle.

Desarrollando la idea apuntada con anterioridad, MAYOL estudia principalmente si la actuación de la víctima encaja dentro de los límites conceptuales de la necesidad de defensa, sin olvidarse, claro está, de la existencia de una agresión ilegítima, presupuesto básico sin el cual no nace la necesidad de defenderse. MAYOL identifica este concepto con el requisito legal de la necesidad racional del medio empleado para impedir o repeler la agresión (art. 20.4 C. P.) ${ }^{18}$. Ello implica, en primer lugar, la existencia de una necesidad de defensa abstracta, la cual debe ser idónea para evitar el peligro de lesión. Por tanto, en los casos en que el agredido utilice la vía de la autolesión para defenderse, ésta debe ser ex ante objetivamente idónea para evitar la realización del peligro amenazante y, a su vez, esta acción defensiva autolesiva no puede generar un peligro para los bienes jurídicos de terceros ${ }^{19}$. Si se dan estos presupuestos existirá una necesidad en abstracto de la acción de autoprotección lesiva. Pero, en segundo lugar, la necesidad racional del medio también debe hacer referencia a su empleo concreto: la utilización del medio menos lesivo pero al mismo tiempo eficaz para impedir o repeler la agresión. Si se dan ambas vertientes del requisito, ello daría lugar, en los supuestos normales de una acción de salvaguarda en donde se lesionan bienes jurídicos del propio agresor, a justificar la actuación -junto con la afirmación del resto de requisitos de la legítima defensa-. Sin embargo, para MAYOL, la falta de necesidad de defensa en abstracto en el grupo de casos objeto de análisis da lugar, en principio, a la no imputación del resultado al autor. Ahora bien, si la necesidad de defensa en abstracto existe, pero no así la necesidad de la utilización de ese medio defensivo en concreto, tampoco habrá imputación objetiva del resultado completa a la conducta del autor (agresor); y mantiene entonces que las diferentes soluciones que se aplican en la denominada institución de la "concurrencia de culpas" son de perfecta traslación a los supuestos de acciones defensivas de carácter autolesivo, debido a la relación de similitud en la que se encuentran ambos grupos de $\operatorname{casos}^{20}$. De

18. El concepto "necesidad de defensa" no se puede incluir, como hace MAYOL (ibíd., p. 57), por completo en el requisito del apartado 2. . artículo 20.4. Sólo la necesidad de defensa en concreto -de naturaleza inesencial- está incluida en el requisito legal de la necesidad racional del medio empleado para impedir o repeler la agresión. Sin embargo, el concepto de necesidad de defensa no se agota ahí, sino que debe existir una necesidad en abstracto -requisito esencial y anterior a la necesidad en concreto- de impedir o repeler la agresión y que el Código Penal ya menciona en la propia descripción de la eximente cuando dice "el que obre en defensa..." (art. 20.4). Por ello, no se puede inferir, como MaYol mantiene, que del requisito de la necesidad racional del medio empleado se deduzca también la exigencia legal de una necesidad de defensa en abstracto, entendida ésta como una necesidad de defensa genérica en la que se exige una idoneidad cualitativa. Ello rompería con la interpretación sistemática interna del artículo, que con muy buen criterio ha diferenciado y ha recogido en primer lugar los requisitos esenciales en la propia definición de legítima defensa y posteriormente ha enunciado los requisitos inesenciales. Cfr. LuZón Peña. Curso PG I, Madrid, Universitas, 1996, pp. 598 y ss.

19. APen 2001, p. 58.

20. Así explica MAYol. Ibíd., p. 59, que "En la concurrencia de culpas coincide una acción imprudente del autor con una imprudencia de la víctima. Tenemos a dos sujetos distintos que son corresponsables, en mayor o menor medida, del resultado lesivo concreto que tiene lugar. En los supuestos de acciones de 
este modo, expone que si la víctima introduce un nuevo factor de riesgo que junto con el riesgo creado por la conducta del autor produce el concreto resultado, se puede, según los casos, (1) o bien excluir la imputación objetiva del resultado al autor, (2) o bien considerar menos grave la conducta del autor, lo cual podría tenerse en cuenta en el ámbito del injusto considerando la imprudencia, en principio, grave como leve; o se dejaría tal cuestión para la determinación de la pena, sin influir en ningún caso en la mayor o menor gravedad de la norma que es infringida por el autor ${ }^{21}$.

Para finalizar con los requisitos inesenciales de la legítima defensa, MAYOL considera que la víctima no debe haber provocado la situación de necesidad, diferenciando entre si esta provocación es intencional o no. En el primer caso no habrá imputación objetiva al autor y el resultado autolesivo entrará plenamente en la esfera de responsabilidad de la víctima. Si, por el contrario, la provocación de la situación de defensa no es intencional, "dependerá de si ésta es suficiente o no para que el resultado se le pueda imputar completamente al autor (agresor) -en caso de que no sea suficiente- o (sic) estemos otra vez ante una problemática similar a la de la concurrencia de culpas"22.

Hasta aquí el repaso a los requisitos objetivos; pero el análisis no estaría completo: para MAYOL faltaría por explicar el elemento subjetivo de la legítima defensa en estos supuestos. Siguiendo con la ubicación de la problemática en el tipo objetivo, según esta autora, la ausencia del elemento subjetivo, por el que se exige que el agredido-víctima sepa que se defiende de una agresión ilegítima, lleva aparejada la ausencia de imputación objetiva, con lo que, si la víctima se autolesiona sin saber que es objeto de una agresión, sólo a ella se le debe imputar el resultado de su acción, aunque esto no sería óbice para considerar, como lo hace MAYOL, que en la conducta del agresor sigue existiendo un desvalor de la acción que no puede quedar sin castigo y que constituirá un delito de tentativa imposible, punible siempre y cuando se haya obrado con dolo ${ }^{23}$.

Con la defensa de esta tesis y volviendo al segundo caso del auto-stop, objeto de la sentencia, MAYol expresa su desacuerdo con la fundamentación del fallo. En primer lugar-afirma-, porque el criterio de la proporcionalidad entre males, utilizado por la sentencia, no rige en la legítima defensa, a no ser que la autolesión que la víctima se produce sea absolutamente desproporcionada frente a la situación de peligro creada por el autor. En segundo lugar, porque los bienes jurídicos en peligro son, además del patrimonio y la integridad física, también la libertad ambulatoria de la víctima, ya que JoAquín se niega a detener el coche cuando Iván se lo solicita ${ }^{24}$. Dicho esto, la

autoprotección que recaen sobre la propia víctima cuando ésta no reacciona a la agresión del autor con el medio eficaz menos lesivo que tenía a su alcance, también podemos decir que ambos sujetos (agresor y agredido) son corresponsables, en mayor o menor medida, del resultado concreto lesivo que se produce la víctima (agredido)".

21. APen 2001, p. 59. Esas tres posibilidades, que señala MAYOL, coinciden plenamente con las que LUZÓN PeÑa. Curso PG I, 1996, pp. 526 y 527, indica como posibles en la concurrencia de culpas (además de la exclusión dela autoría).

22. Ibíd., 2001, p. 60.

23. Ídem.

24. Ibíd., p. 62. 
solución a este caso de MAYOL desde los límites de la imputación objetiva interpretados desde los principios rectores de la legítima defensa es bien diferente. Siguiendo el orden lógico de los requisitos de la legítima defensa, MAYOL considera que ha habido por parte de JoAQuín una agresión ilegítima, actual, dolosa ${ }^{25}$ y antijurídica. Ello crea una situación de necesidad de defensa en abstracto, e IvÁN reacciona con un medio idóneo para evitar el ataque; pero la necesidad de defensa también debe concretarse en la utilización del medio menos lesivo. Según MAYOL, IvÁN reacciona frente a esta situación injusta con el medio menos lesivo, que era tirarse del vehículo en marcha, una vez que ya había intentado persuadir al agresor para que se detuviese, incluso avisándole de que se tiraría del vehículo, por lo que también existe necesidad de defensa en concreto. Ya sólo quedaría por plantear si Iván ha provocado de alguna manera la situación de necesidad de defensa, ya que él accedió voluntariamente a subir al coche. MAYOL contesta negativamente, ya que realizar una actividad que implique riesgos estadísticos de lesión no supone un argumento lo suficientemente convincente para hablar de provocación por parte de la víctima. En cuanto al elemento subjetivo de la legítima defensa, MAYOL no duda de su concurrencia. Por todo ello, concluye que se dan íntegros los requisitos de la legítima defensa, por lo que la acción de la víctima es una conducta de autoprotección y, por tanto, el resultado de lesiones sufrido por Iván sólo y exclusivamente es imputable a JOAQUín.

\section{B. LA SOLUCIÓN DE BONET ESTEVA}

Bonet Esteva parte, en primer lugar, de que el comportamiento de la víctima debe ser relevante para el Derecho Penal, siendo éste un elemento dinámico más del proceso de interacción que es el delito. Ahora bien, el problema estriba en saber cuándo es relevante el comportamiento de la víctima para el Derecho Penal, en otras palabras, qué requisito o conjunto de requisitos debe reunir la actuación de la víctima para que su intervención tenga consecuencias jurídico-penales. BONET lo encuentra en la necesidad de que la víctima actúe de forma libre y consciente ${ }^{26}$, y ya sólo quedaría por

25. Aunque creo que también es posible defender que la conducta de JoAQuín es dolosa en un principio, ya que su finalidad última es consumar un robo, pero no se mantiene esa intensidad en la voluntad en todo momento, y por ello también sería posible sostener que con respecto a su ulterior comportamiento agresivo, mediante el cual pone en peligro la vida o integridad física de Iván al no querer parar el coche, obra con imprudencia consciente. Si esto fuese así, ya no estaríamos ante una agresión ilegítima que fundamentase la legítima defensa, sino que la víctima podría actuar en estado de necesidad defensivo (cfr. LuZón Peña. Aspectos esenciales de la legítima defensa, 2. a ed., Barcelona, Bosch, 1978, pp. 475, 493 y 494, Montevideo y Buenos Aires, J. C. Faira, 2002, pp. 570 y 571; íD. "Legítima defensa y estado de necesidad defensivo", en ComLP v, 1985, pp. 269 y 270; EPen, 1991, pp. 157 y 158; Curso $P G I, 1996$, pp. 632 y 633), pero habría que preguntarse si también sería posible reinterpretar los requisitos de la imputación objetiva con la aplicación de los principios y criterios del estado de necesidad. En mi opinión, esto no hace más que poner al descubierto una vía de posible crítica a la construcción de MAYOL, que se desarrolla en el texto posteriormente.

26. Bonet Esteva. La víctima del delito. (La autopuesta en peligro como causa de exclusión del tipo de injusto), Madrid, McGraw Hill, 1999, pássim y en particular pp. 241 y ss.; íD. "Los límites de la exclusión del tipo de injusto por conducta auto-defensiva de la víctima", en RDPP 2, 2000, pp. 164 y 165, y 167. 
saber qué efectos tiene. Pues bien, las consecuencias de la actuación libre y consciente de la víctima en la teoría del delito encuentran su lugar sistemático en el tipo de injusto, pues es allí donde BONET ubica esta problemática, rebajando la gravedad del tipo de injusto realizado por el sujeto activo o excluyendo incluso el tipo a través de la negación de la imputación objetiva ${ }^{27}$. Teniendo en cuenta la tesis de partida, expone que la formación de la voluntad de la víctima es clave en cualquier caso y, por supuesto, en este en concreto, en el que se debe recurrir al concepto de intimidación, conseguida a través de la puesta en conocimiento a la víctima de la existencia de una navaja -siendo irrelevante si este instrumento existía o no-, de tal modo que ésta pudiera percibir un peligro firme y creíble para sus bienes jurídicos, lo que le lleva a realizar una conducta autodefensiva provocada por un ambiente intimidatorio suficiente ${ }^{28}$. Hasta aquí el argumento principal que esgrime BONET para llegar a la solución, contraria a la que mantiene el Tribunal Supremo, de imputar las lesiones a JoAquín. Pero además, utilizando las propias premisas dogmáticas que maneja la sentencia, como es el criterio de la proporcionalidad entre los males, también llega a la misma solución, ya que, al valorar la amenaza del mal creado por JoAQuín, mantiene que no sólo se debe tener en cuenta el peligro para el patrimonio, sino también para la vida y la integridad física por la especial peligrosidad que entraña el supuesto medio intimidatorio ${ }^{29}$. De este modo, se está afectando con la autodefensa los mismos bienes jurídicos que con la acción intimidatoria, lo que llevaría a imputar las lesiones a JoAQuín.

\section{LA SOLUCIÓN DE CANCIO MELIÁ}

Desde la tesis ya expuesta en su monografía ${ }^{30}$, CANCio Melí́ sostiene que el problema, que plantean estos casos debe ubicarse en el tipo objetivo y solucionarse a través de la teoría de la imputación objetiva y, más concretamente, desde el primer nivel de esta teoría, la imputación objetiva del comportamiento, que es donde sitúa un criterio de valoración denominado "imputación al ámbito de autorresponsabilidad de la víctima”. Según este criterio, no habría imputación objetiva del resultado a la actuación del sujeto activo cuando la víctima (1) crea un riesgo conjuntamente -hay un ámbito de organización conjunta- con el autor, y este riesgo permanece dentro del marco de lo organizado conjuntamente, (2) la víctima no ha sido instrumentalizada por el autor, y (3) además éste no tiene una posición de garantía frente a los bienes de la víctima. Si se cumplen todos estos requisitos, que dan contenido al principio de autorresponsabilidad de la víctima, el riesgo deberá ser imputado al ámbito de responsabilidad preferente de la víctima ${ }^{31}$.

27. Ibíd., pp. 164 y 167.

28. Ibíd., p. 165.

29. Ibíd., p. 164.

30. Cfr. CANCIO Meliá, Conducta de la víctima e imputación objetiva en Derecho Penal: estudios sobre los ámbitos de responsabilidad de la víctima y autor en actividades arriesgadas, Barcelona, J. M. Bosch Editor, 1998.

31. "Los límites de la exclusión del tipo de injusto por conducta auto-defensiva de la víctima", en RDPP 2 (2000), p. 172. 
Utilizando el mecanismo de valoración anteriormente descrito, CANCIO mantiene que en el supuesto de la segunda sentencia del auto-stop es clara la existencia de una “organización conjunta" 32 , pues IvÁn salta del coche por la existencia de una amenaza realizada por JOAQUín. Más problemático le resulta a CANCIO saber si existe una instrumentalización de la víctima por parte del autor, o por el contrario la conducta posterior de ésta constituye una organización autónoma sólo imputable a su ámbito de responsabilidad. Para dilucidar esta cuestión, considera que es especialmente importante tener en cuenta la percepción de la situación por la víctima: si ésta entendía o no razonablemente un posible ulterior daño a su integridad física e incluso a su vida. Para CANCIO, la víctima, en este caso, no se encontraba bajo la presión necesaria, pues no se hace referencia alguna en los hechos probados que se fuera hacer un uso efectivo de la navaja. Con estas premisas defiende la misma solución a la que llega la sentencia, aunque con una justificación distinta, ya que obvia el criterio de la proporcionalidad y pone el acento en la autorresponsabilidad de la víctima, al considerar que IvÁN no es un instrumento en las manos del autor (JOAQUín) y que todavía es responsable ${ }^{33}$.

\section{LA SOLUCIÓN DE GARCÍA ÁLVAREZ}

Aunque García Álvarez valora positivamente la postura abierta a nuevos planteamientos de nuestra jurisprudencia, como es la participación de la víctima en la estructura del delito ${ }^{34}$, volviendo al caso concreto, muestra su disconformidad con la solución de la sentencia ${ }^{35}$ y defiende la responsabilidad del conductor. GARCíA ÁLVAREZ centra el problema que presentan estos supuestos en la autoría, y más concretamente en la figura de la autoría mediata, por lo que analiza la voluntariedad de la decisión del que se autolesiona para decidir sobre la existencia de instrumentalización, relación básica que se debe establecer en esta figura de autoría. De este modo, considera que aunque materialmente sea IvÁn el que se lesiona, no es suficiente el criterio de realización de propia mano para establecer un dominio absoluto sobre el hecho y predicar la autoría de la víctima ${ }^{36}$. Habría que completar este criterio con la existencia de voluntariedad en la decisión del propio titular del bien jurídico de autolesionarse o autoponerse en peligro y así descartar cualquier posibilidad de instrumentalización. Pues bien, en este caso García Álvarez mantiene que la decisión voluntaria queda

32. Este criterio no está, en mi opinión, suficientemente explicado en el comentario a la sentencia, y, al contrario de lo que pueda parecer, no resulta una cuestión baladí, pues considero que no es tan clara su afirmación. Sobre el concepto que defiende CANCIO de "organización conjunta", cfr. Conducta de la víctima, cit., pp. 290 y ss.; y respecto de esta cuestión infra.

33. $R D P P 2,2000$, p. 173. Sin embargo, en la primera sentencia del auto-stop, el también llamado "caso del salto del camión", CANCIO (ob. cit.) considera que la amenaza de un mal, como era la próxima comisión de un delito contra la libertad sexual, sí tenía virtualidad suficiente para crear una instrumentalización e imputar las lesiones al conductor del camión.

34. "Los límites de la exclusión del tipo de injusto por conducta auto-defensiva de la víctima", cit., p. 174

35. RDPP 2, 2000, p. 175 .

36. Ídem. 


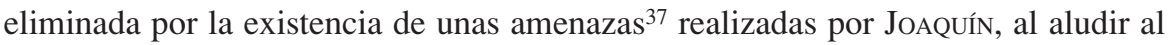
uso de una navaja que portaba en el caso de que IvÁn no le diese su reloj. Y precisamente esto es lo que no tiene en cuenta la sentencia cuando hace su juicio de proporcionalidad, ya que no se trata tan sólo de la pérdida material de un simple reloj, sino que el Tribunal Supremo se olvida de que existe una amenaza, elemento que determina la verdadera dimensión de la situación y la verdadera disyuntiva ante la que se encuentra la víctima: o quedarse en el coche con el riesgo de ser lesionado por el tercero o saltar del coche arriesgando su integridad física e incluso su vida. Por tanto, en contra de lo que mantiene el ponente de la sentencia, GARCíA ÁlvAREz considera que la conducta autodefensiva del menor era proporcional al riesgo que trataba de evitar y constituía además la realización del riesgo creado por el conductor con las amenazas $^{38}$; e incluso, añade, si la víctima crea un riesgo superior al que trata de evitar, siempre y cuando aquél sea razonable conforme a las circunstancias del caso concreto, dará lugar a imputar el resultado al tercero que por medio de amenazas le obliga a que redistribuya "sus bienes jurídicos en una situación similar a un estado de necesidad o en la que se le priva de su capacidad de comprensión y juicio, al no poderse sostener en tal caso la libre disposición de sus bienes jurídicos"39.

\section{E. LA SOLUCIÓN DE TAMARIT SUMALLA}

TAMARIT Sumalla considera que para realizar un adecuado examen de este caso límite hay que centrar la problemática en la imputación objetiva y en la autoría, y precisamente en este orden. Dentro de la categoría de la imputación objetiva, y más concretamente dentro del alcance del tipo, propone delimitar las esferas de responsabilidad de los distintos intervinientes y fijar de este modo el ámbito de lo típico ${ }^{40}$, aunque la cuestión se complica "cuando es el tercero quien ha provocado conscientemente las referidas deficiencias y ha creado la situación peligrosa en la que la víctima ha emprendido la conducta autolesiva"41; pero ello no debe derivar en una solución versarista en la que se impute, según TAMARIT, a la acción inicial injusta cualquier consecuencia. Para evitar este tratamiento erróneo y conseguir una delimitación normativa de la responsabilidad penal, propone el análisis de la imputación objetiva, en la que incluye la idea genérica de la proporcionalidad ${ }^{42}$ como criterio ya analizado y

37. García Álvarez, en RDPP 2, 2000, p. 176, mantiene que, al igual que ocurre en los supuestos de coacciones, puede admitirse la autoría mediata cuando existen amenazas que obligan al titular del bien jurídico a arriesgarlo o a lesionarlo. Ahora bien, como las amenazas por su naturaleza admiten una graduación, GARCía ÁlvAREz hace la salvedad de que no cualquier clase de amenaza será idónea para establecer la relación de instrumentalización. Sólo fundamentará una autoría mediata aquella amenaza "de un mal constitutivo de delito, de tanta entidad como para sumirle en una situación similar a un estado de necesidad (p. ej., amenaza de un delito contra la vida, la integridad física o la libertad sexual); o, de tanta gravedad como para privarle de su capacidad de comprensión o juicio".

38. Ibíd., p. 177.

39. Ibíd., p. 178.

40. "Los límites de la exclusión del tipo de injusto por conducta auto-defensiva de la víctima", cit., p. 179.

41. RDPP 2, 2000, p. 179.

42. Ya sugería TAMARIT la idea de proporcionalidad -aunque no acompañada del atributo de la racionali- 
valorado por la sentencia y que en su opinión constituye uno de los principales aciertos de este fallo ${ }^{43}$; por tal razón, considera que la idea de proporcionalidad se debe valorar en términos normativos acudiendo a la calificación de racional, es decir, atender a si la respuesta de la víctima puede ser calificada de racional ante el ataque a sus bienes jurídicos. Para realizar este juicio de racionalidad, TAMARIT se centra en el "carácter inminente o remoto del peligro que para los bienes jurídicos suponen la agresión y la reacción" ${ }^{4}$, teniendo muy presente las características del caso en concreto. Ello le lleva en el supuesto comentado a mantener la tesis de la impunidad para el conductor, ya que la víctima creó un riesgo mucho mayor que el que trataba de evitar: en primer lugar, porque sólo existió una amenaza genérica sin exhibición de arma; en segundo lugar, porque la víctima tenía una posición objetivamente más ventajosa en cuanto a la capacidad de actuación, ya que JOAQuín iba ocupado en las tareas de conducción, con lo que podía haber aprovechado otras ocasiones en las que el peligro de la huida fuera menor para abandonar el automóvil ${ }^{45}$.

Pasando al estudio de la autoría, siguiendo el orden de análisis ya marcado, TAMARIT ${ }^{46}$ manifiesta que, aplicando el criterio del dominio del hecho, el control sobre el suceso pertenece a la víctima. Así considera, en primer lugar, que la minoría de edad no basta para transferir el dominio al sujeto de atrás, máxime si éste tiene plena conciencia de la entidad de su actuación. En segundo lugar, tampoco considera suficiente para fundamentar la autoría mediata del conductor la existencia de una amenaza previa, incluso si ésta hubiera colocado a la víctima en una situación de inexigibilidad; es decir, la ausencia de una total libertad de actuación de la víctima no puede traducirse automáticamente en la atribución del hecho típico al tercero interviniente ${ }^{47}$. Por tanto, la solución que propone TAMARIT es la de calificar a este tercero interviniente como inductor en una autopuesta en peligro, con lo que su conducta quedaría impune.

dad- en su monografía: La víctima en el Derecho Penal, Pamplona, Edit. Aranzadi, 1998, pp. 107, y 107 n. 20, cuando trataba un caso de la jurisprudencia anglosajona muy parecido al primer caso del auto-stop -peticiones sexuales a una joven que posteriormente salta del vehículo-; pero curiosamente dicho criterio, unido a otros, le llevaba a defender la postura contraria a la que mantiene en este segundo caso del auto-stop. Expone TAMARIT en el lugar citado que "en realidad el caso admitiría una serie de variables decisivas, entre las cuales ocupa un lugar determinante la previsibilidad de la conducta del sujeto pasivo, ya que faltando la misma es llano, según se ha dicho, que el hecho escaparía por completo a la responsabilidad del autor. Y en el caso contrario parece difícil imaginar una exclusiva competencia de la víctima, pues o la reacción es objetivamente proporcionada al comportamiento del autor o, si no lo es, seguramente obedecerá a alguna característica psíquica del sujeto pasivo conocida por el autor -en la medida que resulte por él previsible-susceptible de limitar su imputabilidad y por tanto la responsabilidad por el hecho cometido".

43. RDPP 2, 2000, p. 180.

44. Ibíd., p. 181.

45. Ídem.

46. En estos supuestos, TAMARIT. Ob. cit., p. 181, considera que no se puede sesgar la problemática global que presentan y derivar cualquier solución al análisis de la autoría centrado en determinar si la conducta del tercero guarda una equivalencia estructural con la autoría o por contra supone una simple participación en una autopuesta en peligro.

47. Ídem. 


\title{
III. LAS AUTOPUESTAS EN PELIGRO AUTODEFENSIVAS. PROBLEMAS DE AUTORÍA Y PROBLEMAS DE IMPUTACIÓN OBJETIVA
}

\author{
A. INTRODUCCIÓN: PLANTEAMIENTO DEL PROBLEMA Y \\ UBICACIÓN DENTRO DE LOS ELEMENTOS CONFIGURADORES \\ DE LA TEORÍA DEL DELITO
}

La problemática que presentan estos grupos de casos se encuadra dentro del ámbito del tipo y sobre ello no hay discusión por parte de la doctrina, ya que se trata de averiguar, en un primer término, si la conducta del tercero que interviene en una autopuesta en peligro es típica, sobre todo teniendo en cuenta, ya de entrada, que la propia actuación de la víctima es considerada por el Derecho Penal atípica. Sin embargo, cuando se trata de ubicar la cuestión dentro de las estructuras que conforman la parte objetiva del tipo, la discusión ya no alcanza el anterior grado de consenso. La doctrina en este punto está claramente dividida. Aun considerando que nos enfrentamos ante un problema del tipo objetivo, un grupo de autores considera que las soluciones se encuentran en la interpretación y análisis de la imputación objetiva, sobre todo de sus criterios normativos, como serían el fin de protección de la norma y el alcance del tipo, y otro grupo de autores acude a las estructuras y reglas de la autoría y de la participación para establecer y delimitar responsabilidades penales. La razón de esta marcada división en el tratamiento del problema y sus diferentes fundamentaciones la encuentra GARCÍA ÁLVAREZ en la "previa toma de postura asumida, por cada uno, respecto al concepto de autor que mantienen en los delitos imprudentes" 48 . Pero además en estos supuestos la doctrina acude en muchas de las construcciones al principio de autorresponsabilidad, y apela a la necesidad de delimitar ámbitos de responsabilidad basados en la idea de la autonomía de la víctima.

Por tanto, atendiendo, a la especificidad del caso en concreto de la sentencia, he optado, dentro de la riqueza de matices y multitud de aspectos que plantean las construcciones de la doctrina -y una muestra de ello se ha podido ver en la exposición de

48. García Álvarez. La puesta en peligro de la vida y/o integridad física asumida voluntariamente por su titular, Valencia, Tirant lo Blanch, 1999, p. 316. Sobre el concepto de autor imprudente y el estado de la cuestión en la doctrina alemana y española, así como sobre el concepto unitario de autor imprudente en la dogmática alemana y sus intentos de restringir la responsabilidad penal acudiendo a otras categorías del delito en las que se introducen instituciones como la prohibición de regreso, o principios como el de autorresponsabilidad, cfr. Roso. Autoría, cit., pp. 3 y ss.

Con ello García Álvarez. Ob. cit., 317, n. 5, pp. 359 y ss., no olvida que también se puede dar la posibilidad de intervención dolosa en una autopuesta en peligro, pero en la mayoría de los casos el tercero interviene, explica esta autora, de manera imprudente, lo que ha obligado a buscar las soluciones teniendo muy presente la parte subjetiva de los intervinientes en el hecho. Considero, al igual que GARCía ÁlLAREZ, que ha influido enormemente en el desarrollo de estas cuestiones la concepción de la que se parta sobre la autoría en el delito imprudente, pero tal vez se esté simplificando demasiado, puesto que aquí intervienen otros parámetros como la atipicidad de la conducta del suicida o del que se autolesiona o, con mayor razón, del que se autopone en peligro, que han llevado a algún sector de la doctrina, que será expuesta en el texto, a acudir al principio de la autorresponsabilidad. 
las soluciones a la sentencia- por centrar el análisis en dos cuestiones: 1. Cuándo la coacción o la amenaza constituyen un medio suficiente para fundamentar una relación de instrumentación y convertir, en principio, la autopuesta en peligro en una puesta en peligro dominada o determinada por el sujeto de atrás; 2 . Por otro lado, qué papel desempeña el recurrente principio de autorresposabilidad dentro de las teorías científicas, es decir, si es un criterio normativo dotado de su propio contenido o si es un principio valorativo. Como se verá en el desarrollo de estos temas, seguirá planteándose de una manera implícita o explícita si la problemática que plantea la intervención de la víctima en un hecho, en principio relevante penalmente, es una cuestión de autoría o de imputación objetiva, incluso cuando se analice la autoría mediata, pues algunos autores defienden que la relación de instrumentalización es una cuestión que pertenece a la imputación objetiva ${ }^{49}$. Por último, he optado por exponer las cuestiones en este orden: primero, el análisis de la autoría y, en un segundo lugar, la imputación objetiva, porque, adelantando conclusiones, considero que en el análisis y la interpretación de los criterios de imputación objetiva se tiene que tener en cuenta la concreta forma que adopta la intervención del sujeto activo en el hecho ${ }^{50}$.

\section{B. LA AUTORÍA MEDIATA EN VIRTUD DE COACCIÓN O AMENAZA EN SUPUESTOS DE AUTOPUESTAS EN PELIGRO: EL CONCEPTO DE COACCIÓN O AMENAZA}

\section{Introducción}

La actuación del tercero en una autopuesta en peligro de la víctima que termina en una autolesión es atípica, siempre que la víctima haya actuado libre y voluntariamente, lo que se traduce en un acto libre y voluntario de disposición sobre sus bienes jurídicos, y añadiendo, como presupuesto a esa opción libre y voluntaria, el conocimiento sobre el riesgo de su propia actuación. Si se reúnen todos estos elementos, desde una perspectiva normativa centrada en el análisis de la tipicidad, habría que afirmar la "autoría" de la víctima y la creación de un riesgo sólo imputable a su propia y exclusiva conducta, por lo que cualquier intervención en el hecho sólo podría ser una participación, a su vez atípica. Ahora bien, este ataque contra los propios bienes jurídicos y, en consecuencia, la situación de atipicidad -si sólo se tiene en cuenta como centro de imputación la conducta de la víctima- puede crearse por un conocimiento inexacto de la entidad y existencia del riesgo o por una falta de libertad y de voluntad en la decisión tomada de autoponerse en peligro. Estos déficits que sufre la víctima pueden ser, a su vez, creados o aprovechados por un tercero, que pasa a dominar la conducta de la víctima, con lo que se rompe con el principio de accesoriedad y el comportamiento atípico de la víctima pasa a tener relevancia jurídi-

49. Cfr. la solución de CANCIO supra.

50. En este sentido cfr. LuZón PeÑA, en RDCir 1984, p. 280; íd. DPCir, 1985, p. 99; 2., ed., Barcelona, PPU, 1990, p. 96; ÍD. “La 'determinación objetiva del hecho'. Observaciones sobre la autoría en delitos dolosos e imprudentes de resultado", en $A D P C P 1989$, pp. 890 y 891 y n. 8; también en EPen, Barcelona, Edit. PPU, 1991, pp. 200 y 201 y n. 8. 
co-penal; pero no porque la autolesión o la autopuesta en peligro hayan dejado de ser atípicas, sino porque hemos fijado el punto de referencia no sólo en la conducta de la víctima, sino en la intervención del tercero, que ha conseguido invertir el indicio lógico del dominio sobre el curso causal por el que actúa en último lugar a través de una relación de instrumentalización, que recae sobre un sujeto que actúa, en este caso concreto, sin tipicidad. Esta instrumentalización de la víctima, que como he dejado apuntado crea una falta de libertad o de conocimiento del instrumento, se puede conseguir, en la mayoría de los casos, a través del engaño y la violencia o coacción ${ }^{51}$. Debido a la problemática que representa el caso de la sentencia, centraré mi análisis en el estudio de la relación de instrumentalización a través de la coacción.

\section{El concepto psicológico o normativo de coacción o amenaza}

A través del ejercicio de la coacción se puede llegar a dominar el hecho ejerciendo un control sobre la voluntad del instrumento. Esta estructura ha sido denominada por Roxin dominio de la voluntad ${ }^{52}$. En estos casos, el instrumento debe tener dominio de la acción ${ }^{53}$-en nuestra terminología, dominar o determinar objetiva y positivamente el hecho ${ }^{54}$; d de esta manera el sujeto de atrás controla indirectamente el curso de los acontecimientos y directamente la voluntad del sujeto de adelante. Por consiguiente, puesto de relieve el papel del instrumento y los requisitos que debe reunir su conducta desde los parámetros conceptuales de la autoría y de la participación, resulta obligado analizar la fundamentación de la relación de instrumentalización a través de la coacción y, en primer término, el grado de coacción suficiente para que el sujeto de atrás domine u objetivamente determine de modo necesario el curso del hecho a través de la acción de otro que a su vez determina la producción del resultado.

51. Cfr. por todos, Roxin. Täterschaft und Tatherrschaft, 7. ㄹ ed., Berlin, De Gruyter, 2000, pp. 142 y ss.; íD. Autoría y dominio del hecho en Derecho Penal, trad. de la 6. ${ }^{a}$ ed. alemana por Cuello Contreras y Gónzalez de Murillo, Barcelona, Marcial Pons, 1998, pp. 165 y ss.; Díaz y García Conlledo, en EPBCom, 2002, pp. 160 y ss., en especial p. 162.

52. Cfr., por todos, Roxin. TuT, cit., pp. 140 y ss.; íd. Autoría, cit., pp. 163 y ss.

53. Como pone de manifiesto Díaz y García Conlledo. La autoría en Derecho Penal, Barcelona, Ppu, 1991, pp. 646 y 647, la concurrencia de una serie de criterios materiales, como son la existencia de coacción, error, inimputabilidad en el instrumento, etc., sólo explican desde una perspectiva parcial la figura de la autoría mediata, es decir la estructura necesaria para establecer una relación de instrumentalización, pero, "dándose esos criterios, lo importante para saber si el sujeto de atrás es autor o partícipe será determinar si la acción del instrumento es a su vez objetivamente de autoría [...] o sea determina objetivamente y positivamente el hecho o de participación [...] He aquí la importancia de la actuación del instrumento". Cfr. también pp. 649 y ss.; íD. EPBCOm, 2002, pp. 161 y 162. En el mismo sentido, aunque de forma colateral, sin mayor desarrollo y con otra terminología, Roxin. TuT, cit., p. 143; íD. Autoría, cit., p. 165, expone que "el dominio de la voluntad sobre el tenedor del dominio de la acción fundamenta el dominio del hecho".

54. Así LuZÓn PeÑA. ADPCP 1989, pp. 889 a 913; íd. en DPCir, 2. ․ ed., 1990, pp. 107 a 113; íd. en EPen, 1991, pp. 199 a 224; Díaz y García Conlledo. Autoría, cit., pp. 688 y ss.; íd., en EPBCom, 2002, pp. 145 y ss.; Luzón y DíAz. "Determinación objetiva y positiva del hecho y realización típica como criterios de autoría", en AFDUA 1998-1999 (public. en 2000), pp. 53 a 87; también versión alemana en Roxin-FS, 2001, pp. 575 a 608; Roso. Autoría, cit., pp. 532 y ss.; íD. "Los criterios de autoría en el delito imprudente", en TSJ y AP Aranzadi 21, 2002, pp. 11 a 27. 
La doctrina maneja dos perspectivas para fijar los requisitos de la "suficiencia" de la coacción, como criterio material para fundamentar la relación de instrumentalización. Una perspectiva es el criterio fáctico-psicológico, y el otro enfoque es el normativo ${ }^{55}$. El primero toma como referencia principal el grado de intensidad de la violencia física o de la intimidación, lo cual genera una dependencia de la prueba pericial y la determinación caso por caso de la existencia de autoría mediata o de inducción ${ }^{56}$. El criterio normativo se basa en la ley estableciendo una presunción referida al nivel que debe alcanzar la coacción o la amenaza para justificar la actuación del sujeto de adelante o declararle inimputable. Respecto de esta cuestión, Roxin explica que, si se parte, como él hace, de que el legislador concibe al autor como figura central de la acción típica, como aquel que tiene el curso causal "en sus manos", habrá que preguntarse quién es para el legislador la figura central cuando el sujeto de adelante obra bajo coacción o amenaza, y habrá que seguirse preguntando si la ley ha fijado un límite de capacidad de resistencia humana frente a la coacción y la amenaza ${ }^{57}$. Según Roxin, la ley ofrece puntos de apoyo para saber quién es la figura central, ya que si en determinados casos de coacción o amenaza "el legislador exime de responsabilidad al actuante inmediato -independientemente de su situación anímica en el caso concreto- y le deja tomar impunemente el camino de la mínima resistencia, entonces esto sólo se puede comprender si él (scil. el legislador) ve el suceso, en esta situación, en las manos del sujeto de atrás y a éste le intercala en la posición central del curso causal. Por tanto, el legislador cambia el punto de vista cuando la presión en la motivación ha alcanzado una determinada intensidad y atribuye la responsabilidad sólo al sujeto de atrás, el cual, con ello, se convierte en la figura principal del proceso ejecutivo"58. La segunda cuestión es cuándo la ley cambia el punto de vista y coloca en el centro de la imputación penal al sujeto de atrás. La respuesta la encuentra Roxin en la regulación del estado de necesidad justificante ${ }^{59}$-aunque éste en menor medida- y exculpante ${ }^{60}$. Cuando el sujeto de adelante, según los criterios legales, queda exculpado o se justifica su actuación, el dominio de la voluntad -en la terminología roxiniana- reside en el sujeto de atrás, siempre que éste haya creado o se aproveche de la situación de necesidad. Se basa, por tanto, en el principio de responsabilidad e inexigibilidad con el contenido que la ley le otorga.

¿Cuál es el criterio que se debe seguir? Roxin critica el criterio fáctico-psicológico desde un punto de vista metodológico, ya que "los datos empíricos, aquí la comprobable presión en la motivación de una situación determinada, son ciertamente esenciales

55. Sobre esta cuestión, cfr. Hernández Plasencia. La autoría mediata en Derecho Penal, Granada, Edit. Comares, 1996, pp. 142 y ss.; García Álvarez. Puesta en peligro, cit., pp. 177 y ss.; Bolea Bardón. Autoría mediata en Derecho Penal, Valencia, Tirant lo Blanch, 2000, pp. 261 y ss.

56. Repecto a esta posición y su valoración crítica, cfr. HeRnándeZ Plasencia. Ob. cit., pp. 142 y ss. De manera crítica, Roxin. TuT, cit., p. 146; íD. Autoría, cit., p. 168.

57. TuT, cit., p. 146; Autoría, 1998, p. 168.

58. TuT, cit., pp. 146 y 147; Autoría, cit., pp. 168 y 169.

59. TuT, cit., pp. 149 y ss.; Autoría, cit., pp. 171 y ss.

60. TuT, cit., pp. 153 y ss.; Autoría, cit., pp. 175 y ss.; en $L K, 11 .^{a}, 1992, \S 25$, n. 66 . 
para la regulación legal, porque prestan al concepto del dominio de la voluntad claridad y realismo; pero ellos no pueden determinar el contenido del 'dominio', porque el contenido de significado jurídico de un proceso no puede desprenderse del mero dato psíquico, sino que sólo se puede determinar en coherencia con el sentido legal" 61 . Por otro lado, habría que establecer caso por caso la existencia de autoría mediata o de inducción. Sin embargo, el concepto normativo introduce como ventaja más palpable la seguridad jurídica, ya que atiende a los requisitos legales de las causas de justificación y de exculpación, que a su vez han sido objeto de un gran desarrollo dogmático. Quizás ésta haya sido la razón por la que se ha impuesto el criterio normativo ${ }^{62}$ frente al psicológico, tanto en la doctrina alemana como en la española, quedando la discusión reducida a qué clase de estado de necesidad debe ser el que imponga los límites de la suficiencia de la coacción para establecer la relación de instrumentalización. Las posturas se dividen entre los que consideran que el único estado de necesidad aplicable es el exculpante ${ }^{63}$ y quienes aceptan tanto éste como el estado de necesidad justificante ${ }^{64}$ para fijar los contornos de la coacción suficiente.

En efecto, aplicando el $§ 35$ ("estado de necesidad disculpante") del StGB, habrá autoría mediata cuando el sujeto de atrás coloque al sujeto de adelante en una situación de inexigibilidad penal, debido a la creación de un peligro actual para su vida, su integridad física, su libertad o la de algún familiar o persona cercana. En estos casos, se considera que el sujeto que realiza un hecho antijurídico obra sin responsabilidad. $\mathrm{Si}$, por el contrario, acogemos la tesis que se fundamenta en la aplicación del $\S 34$ ("estado de necesidad justificante") del StGB, el sujeto de atrás debe crear una situación de peligro para los bienes jurídicos: vida, integridad física, libertad, honor, pro-

61. TuT, cit., p. 146; Autoría, cit., p. 168.

62. Cfr. la exposición de posiciones críticas contra la tesis normativa en Hernández Plasencia. Autoría mediata, cit., pp. 155 y ss.

63. El representante principal de esta opción, como ha quedado reflejado en el texto, es Roxin, pero también otros autores alemanes han optado por esta posición; así, entre otros, CRAMER en SCHÖNKE y SChröDER, 26.. , § 25, n. ․ 10; BotTKE. "Probleme der Suizidbeteiligung", en GA 1983 pp. 31 y ss.;

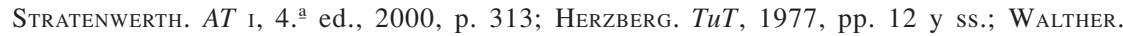
Eigenverantwortlichkeit und strafrechtliche Zurechnung. Zur Abgrenzung der Verantwortungsbereiche von Täter und Opfer bei riskantem Zusammenwirken, Freiburg, Max-Planck-Institut, 1991, pp. 192 y ss. En España sigue la tesis de Roxin, aunque critique y no comparta su construcción global basada en las diferencias entre autopuestas y heteropuestas en peligro, CANCIO. Conducta de la víctima, cit., pp. 360 a 362; en particular críticas y toma de posición, pp. 361 y 362. No siguiendo esta postura y reflejando las críticas de otros autores, cfr. HeRnÁndez PlasenCIA. Ob. cit., pp. 245 y 246.

64. Así, entre otros, en Alemania, JAKoBs. AT, 2. a ed., 1991, pp. 638 y ss.; íD. PG, trad. de la 2. ed., alemana por Cuello Contreras y Serrano González de Murillo, 1997, pp. 771 y ss.; sobre esta postura de JAKOBS, cfr. CANCio. Conducta de la víctima, cit., p. 361, n. 472; en España, Bolea Bardón. Autoría mediata, cit., pp. 267 y 268 y 286 y ss., quien defiende un criterio normativo para establecer la existencia de coacción en los casos de situaciones de necesidad que pueden exculpar la conducta del sujeto de adelante, pero con ciertas reservas, puesto que, en su opinión, no siempre que falte la responsabilidad penal por un estado de necesidad exculpante o por miedo insuperable se puede entender que automáticamente habría autoría mediata; y centrándose específicamente en los supuestos de autopuestas en peligro o autolesiones, es decir, que el instrumento sea al mismo tiempo sujeto pasivo, González Cussac y Mira Benavent, en L-H Cerezo, 2002, pp. 729 y ss. 
piedad o cualquier otro bien jurídico del sujeto de adelante o para otra persona, y el instrumento, creada la situación de coacción por el sujeto de atrás, actuará conforme a Derecho siempre y cuando en la ponderación de intereses prevalezca sustancialmente el interés salvado y además la realización de ese hecho antijurídico haya sido el medio adecuado para evitar ese peligro.

Ahora bien, estas soluciones se han pensado para supuestos en los que es necesaria la justificación o la exculpación de una conducta típica, puesto que el instrumento actúa lesionando bienes de terceros. La cuestión que se plantea, entonces, es si es posible extrapolar estas mismas respuestas a supuestos en los que el sujeto se defiende de modo atípico poniéndose a sí mismo en peligro. La mayoría de los autores responden afirmativamente, y, recurriendo a la analogía, aplican estas mismas soluciones, planteándose, a su vez, la misma división de opiniones a la hora de optar por la aplicación del estado de necesidad justificante o por el disculpante. JAKOBS ha optado abiertamente en estos casos por la aplicación analógica del estado de necesidad ${ }^{65}$ justificante y por considerar que es autor mediato aquél que coloca a la víctima en la necesidad de atentar contra sus propios bienes, siempre que la actuación de ésta se ajuste a la proporcionalidad establecida en el estado de necesidad justificante ${ }^{66}$. Así se estará ante una situación de cuasi-justificación y la víctima tendrá solamente un dominio sobre la decisión subordinado. Sin embargo, al haber una identidad de sujetos -ya que los bienes o intereses jurídicos que se intenta salvar a costa de otros bienes pertenecen al mismo titular-, JАКовS considera que en estos supuestos el requisito de la proporcionalidad entre los intereses jurídicos, cuyo fundamento se encuentra en la solidaridad interpersonal, debe ser interpretado de modo más laxo, ya que aquí no es válida dicha limitación ni su fundamentación, pues el acto de disposición no se hace sobre un bien jurídico ajeno, sino en el bien jurídico propio. Es decir, "la configuración básica del estado de necesidad justificante, el estado de necesidad agresivo, contiene un elemento que no cuadra en el caso de la autolesión: el requisito de que el daño causado sea considerablemente inferior al interés que se preserva. Este requisito de la concurrencia de una utilidad considerable tiene una buena razón en la configuración básica, ya que se trata de intervenir en los intereses de una persona que no tiene nada que ver con el peligro que hay que evitar: se pretende que la persona no implicada no tenga que soportar la solución del conflicto a su costa a cambio de cualquier ventaja pequeña, sino en el caso de que el daño que pueda producirse sea considerable, de manera que el perjuicio de quien debe tolerar la intervención sea considerablemente inferior. Sin embargo, si los intereses a sacrificar y los que deben preservarse pertenecen a una sola persona, la redistribución de los intereses es adecuada mientras haya cualquier tipo de ventaja, más aún, mientras no se obtenga un

65. Desde esta perspectiva JAKOBS. AT, 2. ․ ed., cit., p. 643; íD. PG, 2. ․ ed., cit., p. 776; Estudios de Derecho Penal, Peñaranda Ramos, Suárez González y Cancio Meliá (trads.), Madrid, Edit. Civitas, 1997, pp. 407 y 408, incluye supuestos que tradicionalmente se consideraban de autoría mediata a través de instrumento cuasi-exculpado, y así lo reconoce el propio autor.

66. JАKOBS. $A T, 2 .^{\mathrm{a}}$ ed., cit., p. 642 ; ÍD. $P G, 2 .^{\mathrm{a}}$ ed., cit., p. 775. 
resultado irracional"67. Por esta razón, JAKOBS considera que en los casos que nos ocupan "existirá autoría mediata, mientras que la jerarquía de valores practicada por la víctima sea en general plausible"68.

En la doctrina española, las soluciones y argumentos no se apartan mucho de los aportados por la doctrina alemana, pese a que la regulación jurídica en este caso es distinta -en el Código Penal no existe un precepto paralelo al $\S 35$, y sólo en parte como el $\S 34$, del StGB-; sin embargo, ello no constituirá ningún obstáculo para poder mantener las mismas consecuencias que en el ordenamiento jurídico-penal alemán ${ }^{69}$. Pasando a las argumentaciones de la doctrina, GARCíA ÁlvAREz considera que antes de nada lo que debe concurrir en estos casos es la existencia de violencia, en la que engloba tanto su vertiente física como la intimidación personal ${ }^{70}$. Una vez planteado el presupuesto inicial, igualmente mantiene que la coacción, para que sea suficiente y sea apta para crear una relación de instrumentalización, debe crear "una situación similar a la que permite apreciar estado de necesidad"71 -y añade, en los casos de coacción a una autolesión- "o un estado que le priva de la capacidad natural de comprensión y juicio para entender el alcance de la conducta de riesgo que emprende" "72. García Álvarez defiende, en mi opinión, una tesis sincrética, porque no sólo estima que hay autoría mediata cuando la coacción crea un estado de necesidad -al que por cierto otorga siempre la naturaleza de causa de justificación, independientemente del valor jurídico de los intereses o bienes en conflicto ${ }^{73}$-, sino también cuando la coacción prive a la víctima de la capacidad natural de entender las consecuencias de la conducta arriesgada, con lo que se acerca mucho a supuestos de inimputabilidad. A todo ello hay que sumarle el juicio de racionalidad, aproximándose de este modo a la postura de JAKOBS, al que acude para argumentar su solución en la segunda sentencia del auto-stop -objeto de este comentario- ${ }^{74}$. Por su parte, CANCIO se muestra partidario, junto con la doctrina mayoritaria alemana, de establecer la autoría mediata cuando la coacción coloque al instrumento ante una situación análoga al estado de necesidad exculpante, "ya que el ordenamiento, al establecer los criterios del estado de necesidad exculpante, ha fijado el umbral de presión psíquica que

67. JAKoBs. Estudios, cit., p. 407.

Cfr. las críticas de CANCio. Conducta de la víctima, cit., pp. 361 y 362, sobre esta posición y sobre el empleo del criterio de la racionalidad.

68. JAKOBS. AT, 2. ${ }^{\mathrm{a}}$ ed., cit., p. 642; íD. $P G, 2 .^{\mathrm{a}}$ ed., cit., p. 776.

69. Aunque para la doctrina española que defiende que todo estado de necesidad es siempre causa de justificación (en la que me incluyo), pese a que los intereses en conflicto sean de la misma entidad, la discusión mantenida en la doctrina alemana y parte de la española sobre si la coacción debe crear en el sujeto coaccionado una situación de necesidad disculpante o justificante no tiene mucha razón de ser.

70. Puesta en peligro, cit., pp. 177 y 260.

71. Ibíd., pp. 180 y 260.

72. Ibíd., p. 260.

73. Ibíd., pp. 181 y 181, n. 183.

74. Cfr. la solución de la autora expuesta supra. 
se espera que pueda resistir un sujeto (constitucionalmente) imputable"75. Esta tesis es metodológicamente defendible, como ya se ha visto, pero CANCIO se olvida de entroncar esta solución con la regulación española. FEIJóo, siguiendo a JAKOBS, mantiene que no hay verdaderas autolesiones o autopuestas en peligro cuando la única salida racional que le queda a la víctima ante una situación de necesidad creada por un tercero es la de autolesionarse o autoponerse en peligro ${ }^{76}$. Una vez dicho esto habría que establecer los márgenes de la racionalidad, y para este autor el juicio de racionalidad $^{77}$ equivale, al igual que para JАKOBS, a la aplicación de las reglas del estado de necesidad del artículo 20.5 C. P. ${ }^{78}$-en el que sólo cabe según este autor el estado de necesidad justificante y no el exculpante ${ }^{79}-$ y con el límite del principio de proporcionalidad. Por tanto, la autolesión no debe ser de mayor entidad que la probable lesión de bienes jurídicos. Ello le lleva a sostener que no hay racionalidad y, por tanto, verdadera autolesión en el caso de la primera sentencia del auto-stop, pues "no es racional que una mujer se tire de un camión en marcha porque el camionero intenta convencerle de forma grosera de que mantengan una relación sexual, pero puede llegar a ser una reacción racional ante un inminente ataque contra su libertad sexual o contra cualquier otro bien personal frente al que no cabe otra salida" 80 . Ahora bien, para que haya autoría mediata no basta con la existencia de una coacción, sino que "es preciso que el que haya creado la situación haya disminuido las posibilidades de elección de la víctima y por ello la víctima se vea afectada en el 'dominio sobre la decisión' sobre sus propios asuntos quedando así excluida su responsabilidad sobre el hecho" 81 .

Por su parte, recientemente, González Cussac y Mira Benavent consideran que el estado de necesidad justificante no puede ser el único concepto que delimite la cuestión de la responsabilidad de la víctima en los supuestos de coacción, y ello por tres razones $^{82}: 1$. La sola y exclusiva utilización de los parámetros del estado de necesi-

75. Conducta de la víctima, cit., p. 361. Cfr. supra nota 64.

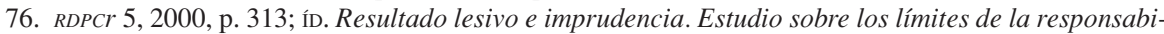
lidad penal por imprudencia y el criterio del "fin de protección de la norma de cuidado", Barcelona, J. M. Bosch Editor, 2001, p. 374.

77. Sin embargo. FeiJóo. Resultado lesivo, cit., p. 375, al igual que JAKOBS, también acude al principio de solidaridad y con base en él manifiesta que "la necesidad y racionalidad se determina a través de una ponderación de utilidad global o intereses colectivos, ya que en una sociedad integrada en la que no sólo la idea de solidaridad está recogida como un interés importante (omisión del deber de socorro) sino también es una idea rectora de nuestro ordenamiento jurídico es razonable sacrificarse en beneficio de otros. Todos los bienes jurídicos tienen una vertiente social o solidaria que hace que ciertos sacrificios sean asumibles por el ordenamiento jurídico. El ejemplo más claro es el de la regulación del estado de necesidad (art. 20.5 C. P.). Pues bien, no hay ninguna razón para considerar acertado todo sacrificio de un bien ajeno en beneficio de un interés preponderante pero no el sacrificio de los bienes propios en beneficio de un interés de mayor relevancia social o para evitar un mal de mayor entidad. Es decir, una autolesión que en principio puede parecer de exclusiva incumbencia de la víctima puede dejar de serlo si se ve motivada por una situación de necesidad creada por un tercero".

78. RDPCr 5, 2000, p. 314; Resultado lesivo, cit., p. 374.

79. $R D P C r 5,2000$, p. 314, n. 124.

80. Ibíd., p. 315.

81. Ibíd., p. 316.

82. L-H Cerezo, 2002, p. 729. 
dad para valorar la "razonabilidad" de la conducta de la víctima que se pone en peligro para evitar un riesgo creado por el autor aumenta los casos de imputación del resultado al ámbito de responsabilidad de la víctima y disminuye los de responsabilidad del autor, puesto que también el estado de necesidad exculpante, el miedo insuperable o cualquier otro supuesto de inexigibilidad constituyen igualmente salidas razonables frente a riesgos relevantes jurídicamente; "por lo que dejar a la víctima como única salida la posibilidad de defenderse sólo si concurren los requisitos del estado de necesidad justificante sería tanto como obligarle a soportar de forma impertérrita el peligro creado por el autor (y que éste siguiera su curso) en los demás casos, sobre todo teniendo en cuenta que esto no ocurre en otros ámbitos" $" 83$. 2. Partiendo de la consecuencia lógico-sistemática de que los supuestos de autolesión o autopuesta en peligro no son típicos, y por tanto no sería necesario justificar, GonZÁLEZ Cussac y Mira Benavent manifiestan que es menos comprensible todavía que el legislador haya otorgado una amplia gama de causas de justificación y de inexigibilidad al "autor" de una lesión a un bien jurídico y se restrinja el elenco en el caso de la víctima que no pone en peligro ningún bien jurídico de tercero, sino exclusivamente los suyos propios. "Pues si no se atribuye con carácter general responsabilidad a quien lesiona un bien ajeno, concurriendo una situación de necesidad exculpante o de miedo insuperable, tampoco se deberá atribuir responsabilidad a la víctima que decida autolesionarse o autoponerse en peligro en las mismas circunstancias. No puede hacerse de peor condición el ámbito de responsabilidad de la víctima que el del autor de cualquier delito, sobre todo teniendo en cuenta además que aquélla juega con bienes propios y éste lo hace con bienes ajenos" 84 ; 3 . Por último, no ven inconveniente ninguno para determinar los casos en los que la conducta coactiva del autor es la base explicativa de la falta de responsabilidad de la víctima, el admitir, siguiendo a Cancio Meliá, los criterios del estado de necesidad exculpante, "a través de los cuales el ordenamiento jurídico ha fijado el umbral de presión psíquica que se espera que pueda resistir un sujeto (constitucionalmente imputable); o a criterios como el del miedo insuperable, que vendría a ser aplicable, como estima CUERDA ARNAU, precisamente a casos que no son incardinables en el estado de necesidad si faltan determinados requisitos de este último" $"$.

Dicho esto, hay que considerar, por otro lado y una vez expuestos el contenido y límites normativos del concepto de coacción, si ésta finalmente ha creado un déficit de libertad en la víctima que haga que no sea autorresponsable, bien por falta de imputación objetiva, bien por falta de domino sobre el hecho.

83. Ibíd., p. 730.

84. Ídem.

85. Ibíd., pp. 730 y 731. 


\section{EL PRINCIPIO DE AUTORRESPONSABILIDAD EN LAS AUTOPUESTAS EN PELIGRO: ¿PREMISA AXIOLÓGICA O CRITERIO NORMATIVO DE LA AUTORÍA O LA IMPUTACIÓN OBJETIVA?}

Mucho se ha escrito en las últimas décadas sobre el principio de autorresponsabilidad (Selbstverantwortlichketsprinzip) o de responsabilidad propia (Eigenverantwortlichkeitsprinzip $)^{86}$ o por el propio injusto, y sin embargo ni hay un acuerdo en su denominación, ni en su contenido, ni en qué estructuras dogmáticas deben interpretarse teniendo presente este principio.

LuZón PEÑa entiende el principio de autorresponsabilidad como un límite del ius puniendi y "significa que sólo se puede responder por los hechos propios y no por los hechos ajenos en los que no tenga ninguna influencia ni responsabilidad (por deberes de control) el sujeto"87. Esta definición absolutamente correcta ${ }^{88}$ no contiene todas las acepciones o perspectivas desde las que se explica el concepto de "autorresponsabilidad". La autorresponsabilidad puede ser entendida desde una perspectiva ontológico-psicólogica e incluso filosófica, en la que se valoran las condiciones psíquicas del sujeto arrojando un juicio de normalidad autorresponsable en su caso; pero también se puede conceptuar dicho principio desde una perspectiva jurídiconormativa, basada igualmente en la idea de la autonomía de los actos ${ }^{89}$. En cualquiera de estas dos acepciones, el principio de autorresponsabilidad está presente en los últimos tiempos en multitud de argumentaciones dogmáticas que intentan delimitar la responsabilidad penal; pero, sobre todo, es el principio estrella en dos categorías, a saber, en la autoría, en particular en los estudios referidos a la autoría mediata, y en la imputación objetiva. Algunos autores consideran este principio de autorresponsabilidad como el principio fundamentador $-\mathrm{y}$ yo añadiría limitador del ius puniendi ${ }^{90}-$ del tipo objetivo paralelamente a lo que representa el principio de responsabilidad subjetiva -o de culpabilidad, para la doctrina más tradicional- en la otra parte del tipo positivo y del negativo, la subjetiva ${ }^{91}$.

Como acabo de señalar, el principio de autorresponsabilidad se presenta unido en la mayoría de las construcciones, de manera expresa en ocasiones, otras veces de modo

86. Sobre la utilización indistinta de ambas expresiones y la falta de uniformidad en la terminología, cfr. por todos, CANCiO. Conducta de la víctima, cit., p. 259, n. 6.

87. Curso PG I, cit., p. 88.

88. Es lógico que LuZón Peña no haya contemplado las otras posibles acepciones del concepto de autorresponsabilidad, ya que como límite del ius puniendi no hace falta definir cuándo un sujeto es autorresponsable, sino qué es la autorresponsabilidad.

89. CANCio. Conducta de la víctima, cit., p. 262, explica claramente cómo se manejan dos acepciones del término. Una se utiliza para "designar las bases fundamentadoras de un ámbito de responsabilidad". La otra utilización del término lo considera de carácter operativo, ya que con ella se quiere hacer referencia a "la determinación de los criterios concretos para decidir si una víctima concreta en una situación concreta reúne las características personales necesarias para que pueda afirmarse que su conducta ha sido responsable y que debe por ello influir en la conducta jurídico-penal del comportamiento del autor".

90. Roso. Autoría, cit., pp. 204 y 205.

91. Cfr. Tamarit. Víctima, cit., pp. 101 y 102. 
implícito, a las categorías de la imputación objetiva y de la autoría. Ello, en mi opinión, se debe a que estas dos estructuras dogmáticas son las dos herederas modernas de la vieja problemática de los supuestos de la prohibición de regreso ${ }^{92}$, en la que ya estaba subyacente la idea de la delimitación de ámbitos propios de responsabilidad, puesto que ya entonces la preocupación dogmática principal se centraba en no hacer responsable al sujeto de atrás por lo que realizase el sujeto de adelante cuando éste fuese considerado un individuo libre y responsable ${ }^{93}$. Esta cuestión, que se dirimía en sus orígenes de modo primitivo e intuitivo en la causalidad, se soluciona ahora o bien acudiendo a criterios que se desarrollan dentro de la imputación objetiva -perdiendo ésta, en mi opinión, su verdadera naturaleza y función-, como son la adecuación social, el principio de confianza, el riesgo permitido, o bien a los criterios de autoría. Ahora bien, este problema no sólo se presenta en los casos en los que la conducta de todos los intervinientes en el hecho lesiona bienes ajenos, sino que también se plantea de igual modo en los supuestos en los que uno de los intervinientes resulta ser lesionado en sus propios bienes, y si cabe con mayor interés, pues la consecuencia práctica es la no responsabilidad penal del tercero interviniente en una autolesión o en una autopuesta en peligro que es atípica. Por tanto, la importancia práctica del fenómeno victimodogmático ha dado lugar a que varios autores se hayan ocupado de la incidencia y consecuencias de la presencia de la víctima en la realización del delito y muchos de ellos, tanto en la doctrina española como alemana, hayan utilizado el principio de autorresponsabilidad de una u otra manera, bien como principio axiológico o bien como un criterio normativo con un contenido variable, dentro de sus construcciones, para solucionar aquella vieja problemática que planteaban los casos de prohibición de regreso.

En la doctrina alemana, ZACZYK ${ }^{94}$ concibe el principio de autorresponsabilidad como un concepto prejurídico, que trata de explicar y dota de contenido partiendo de la filosofía práctica de KANT. Así, considera que este principio tiene un significado positivo y general e independiente de la existencia de una norma jurídica, al que no se le

92. Así queda patente, entre otros, en las construcciones de WeLP. Vorangegangenes Tun als Grundlage einer Handlungsäquivalenz der Unterlassung, Berlin, Duncker \& Humblot, 1968, pp. 283 у ss.; Отто. "Vorangegangenes Tun als Grundlage strafrechtlicher Haftung", en NJW, 1974, p. 705; íD. "Täterschaft und Teilnahme im Fahrlässigkeitsbereich", en Spendel-FS, Berlin, De Gruyter, 1992, pp. 277 y ss.; WeHrLe. Fahrlässige Beteiligung am Vorsatzsdelikt-Regrebverbot?, Frankfurt, Helbing \& Lichtenbach, 1986, pp. 83 y ss.; Schumann. Strafrechtliches Handlungsunrecht und das Prinzip der Selbstverantwortung, Tübingen, Mohr, 1986, pp. 6 y pássim; DiEL. Das Regreßverbot als allgemeine Tatbestandsgrenze im Strafrecht, Frankfurt, Lang, 1997, pp. 315 y ss., 330 y ss. Cfr. también al respecto WALTHER. Eigenverantwortlichkeit, cit., pp. 20 y ss., en donde realiza una exposición sistemática de la doctrina alemana, agrupando a los autores según el concepto o institución dogmática a la que han unido el principio de autorresponsabilidad: al deber objetivo de cuidado, a las causas de justificación, a la exclusión de la imputación objetiva y, por último, el principio de autorresponsabilidad como cuestión de delimitación de ámbitos de responsabilidad inspirado en el nuevo principio de responsabilidad defendido por la doctrina moderna.

93. Cfr. Roso. Autoría, cit., p. 201, n. 606.

94. Un estudio en detalle de la tesis de ZACZYK se puede ver en CANCIO. Conducta de la víctima, cit., pp. 264 y ss. 
ha dado un significado originario, ni del que se ha agotado su significado jurídico ${ }^{95}$. Por ello, ZACZYK trata de buscar un fundamento al concepto de autorresponsabilidad, de delimitar el alcance del principio cuando se establece una relación interpersonal y, por último, de reformular el injusto penal a través de este principio, ocupándose en este punto de la responsabilidad de la víctima.

El fundamento de este concepto prejurídico lo encuentra ZACZYK en la libertad ${ }^{96}$. Una libertad autónoma, presidida por la autodeterminación, de tal modo que "la persona no actúa según las leyes, sino que, como ser racional, según la representación de las leyes, es decir, tiene una voluntad"97; y esa voluntad debe actuar inspirada por el imperativo categórico kantiano, buscando la generalidad, es decir, que su actuación se oriente a la consecución de su conversión en una ley general, de tal modo que "el imperativo categórico sea la ratio cognoscendi de la libertad, y ésta la ratio essendi del imperativo categórico"98. "Por tanto, la autorresponsabilidad en sentido jurídico es sólo un segmento, que se fundamenta en la libertad, del marco general de autodeterminación y del ser en sí mismo"99; pero este segmento de la autodeterminación se valora necesariamente en su relación con otras personas y es en este ámbito donde desempeña su papel el Derecho, ya que es un modo de regular las relaciones interpersonales. Por estas razones ZACZYK considera que la autorresponsabilidad tiene un doble significado: por un lado, se trata del uso de la libertad de uno (que es el que actúa) y, por otro lado, se valora la corrección jurídica de su actuación a través del respeto de la libertad del otro. Por ello, "las relaciones interpersonales como relaciones de reconocimiento son relaciones creadas recíprocamente por cada uno de los sujetos de manera responsable"100. Con ello, ZACZYK consigue dar un contenido positivo al concepto de autorresponsabilidad, ya que a través del reconocimiento de la libertad del otro se consigue una conducta correcta del que actúa y por consiguiente se constituye un mundo jurídico común. "El 'marco general de la ley' del imperativo categórico está concretado en su significado recíproco y materializado a través de la existencia libre del otro"101. Con estas premisas, el ordenamiento jurídico no es más que la forma de reconocer e institucionalizar esa ley general, y la institución jurídica de la pena una reacción general a la lesión de la esfera jurídica del otro ${ }^{102}$.

Ahora bien, ZACZYK asciende un escalón más en su construcción y trata de averiguar las implicaciones de la autorresponsabilidad en el Derecho Penal. Así, expone que en los supuestos normales, en los que no existe una intervención de la víctima, el autor

95. Strafrechtliches Unrecht und die Selbstverantwortung des Verletzten, Heidelberg, C. F. Müller, 1993, p. 18.

96. Selbstverantwortung, cit., p. 19.

97. Ibíd., p. 20.

98. Ibíd., p. 21.

99. Ibíd., p. 22.

100. Ibíd., p. 23.

101. Ibíd., p. 24.

102. Ibíd., pp. 24 y 25. Cfr. Cancio. Conducta de la víctima, cit., p. 266. 
comete un injusto que resulta ser la negación del Derecho, ya que subyuga la esfera de libertad de la otra parte de la relación interpersonal ${ }^{103}$. Sin embargo, y ésta es la primera conclusión que extrae, la autolesión no constituye ningún injusto, ya que no existe una relación interpersonal esencial. No obstante, esta afirmación está necesitada de un ulterior desarrollo, constituyendo de este modo el objeto central y de estudio de su tesis, ya que considera necesario establecer los límites de la autolesión a través de criterios que nos indiquen cuándo la conducta de la víctima se encuentra carente de libertad ${ }^{104}$. Para abordar esta cuestión, ZACZYK estudia el fenómeno diferenciando entre distintos supuestos, en los que tratará de comprobar si existe una interacción o relación interpersonal, que dé lugar a la existencia de un injusto o una autolesión que no sea antijurídica. Este planteamiento conduce a que el centro de imputación sea el análisis de la conducta de la víctima, de tal modo que estudia los supuestos en los que la víctima actúa "dolosamente"105, en los que la víctima tiene conocimiento del riesgo ${ }^{106}$ y en los que la víctima tiene cognoscibilidad sobre el riesgo ${ }^{107}$. En los primeros supuestos habrá autolesión como ejercicio específico de la autodeterminación y no habrá injusto, cuando haya una relación de la voluntad, la acción y el resultado como unidad de autodeterminación ${ }^{108}$. Esta unidad se rompe cuando haya una tara o defecto de voluntad debido a la existencia de un error o de una coacción ${ }^{109}$, lo que conduce a plantearse la cuestión de qué vicios de la voluntad deben darse para que estemos de nuevo ante la existencia del injusto del tercero ${ }^{110}$. En los supuestos en los que la víctima tiene conocimiento del riesgo, que constituyen para ZАCZYK los casos de autopuesta en peligro, se impone la referencia continua al injusto imprudente y el criterio a seguir en la autopuesta en peligro no puede ser, a diferencia de los casos de autolesión, la constatación de una unidad de voluntad, de acción y de resultado, debido precisamente a que éste último no es el fin de la acción del sujeto que se pone en peligro ${ }^{111}$, pero ello no significa que todo se reduzca entonces al análisis de la imprudencia del tercero-autor, postergando el principio de autorresponsabilidad y cambiando la perspectiva de estudio de la cuestión, ya no desde la óptica de la víctima, sino del autor ${ }^{112}$. Por tanto, ahora el criterio que sirve para saber si la víctima es autorresponsable o si por el contrario existe un injusto penal es otro bien distinto: la víctima no será autorresponsable si puede confiar desde un punto de vista normativo en que el tercero actuando conforme al deber podía

103. Selbstverantwortung, cit., p. 26.

104. Ibíd., p. 27.

105. Ibíd., pp. 32 y ss.

106. Ibíd., pp. 49 y ss.

107. Ibíd., p. 62.

108. Ibíd., pp. 35 y 64.

109. Ibíd., pp. 37 y ss.

110. Ibíd., pp. 38 y ss., en donde desarrolla qué entidad deben tener esos vicios de la voluntad, especial mente el error, para predicar la autoría y el dominio sobre la acción del tercero, y considera que puede admitirse tanto autoría dolosa del sujeto de atrás como autoría imprudente, dejando a un lado el argumento de la participación (pp. 48 y 49).

111 Ibíd., p. 53.

112. Ibíd., p. 54. 
dominar el curso causal lesivo o incluso, excepcionalmente, aun existiendo una situación de autopuesta en peligro, la víctima podía confiar en el control del riesgo por parte del tercero debido a una posición especial de protección de éste con respecto al bien jurídico ${ }^{113}$. Finalmente, se ocupa del conocimiento potencial del riesgo por parte de la víctima. Debido a la concepción que mantiene del principio de autorresponsabilidad, la lesión caerá dentro de la esfera de la víctima cuando aquélla sea resultado de la manifestación de su voluntad, pero en ningún caso se debe entender la autorresponsabilidad como un deber normativo de autoprotección de los propios bienes jurídicos frente a cualquier curso causal lesivo ajeno. Por ello, en estos casos no existe autorresponsabilidad por parte de la víctima y sí un injusto penal del tercero ${ }^{114}$.

WALTHER concibe el principio de autorresponsabilidad como un principio jurídico rector y necesitado de concreción ${ }^{115}$. Como principio rector, la responsabilidad por hechos propios, aunque no sea un principio escrito en la Constitución, es según WALTHER un componente inmanente que se infiere ya en forma directa de un ordenamiento jurídico democrático y libre, que ha tenido en cuenta la propia estructura humana, extrayendo su contenido nuclear propio, como es la libre autodeterminación dentro de una sociedad libre. En la existencia de esta autodeterminación se acepta, como el reverso de la moneda, una capacidad de responsabilidad personal ${ }^{116}$. Desde estos presupuestos, el paso siguiente consistirá en fijar el contenido posible de un principio de autorresponsabilidad, el cual podría ser, según WALTHER, el siguiente: cada uno es responsable por su actuación propia, mientras que no, o sólo excepcionalmente, se puede ser responsable por la actuación de otro. Pero este contenido no se deriva del principio de capacidad de autodeterminación, sino de la sujeción a una vida en sociedad ${ }^{117}$. No obstante, WALTHER considera que el principio de autorresponsabilidad necesita de una ulterior concreción si se aplica al ordenamiento jurídico-penal, por lo que hay que definir el papel que desempeña dentro de las categorías de imputación penales. Así, al contrario que la mayoría de los autores que establecen una relación directa entre el principio de autorresponsabilidad y la imputación objetiva, WALTHER propone, en su construcción, partir de las delimitaciones ya elaboradas por la doctrina de la autoría y de la participación para trazar los ámbitos de responsabilidad, de tal modo que sólo será responsable de su autopuesta en peligro la víctima que es considerada autor, dependiendo ello del criterio de autoría que se mantenga ${ }^{118}$.

TAmarit Sumalla parte del principio de autorresponsabilidad o, como él lo denomina, principio de la responsabilidad penal o de responsabilidad por el hecho propio ${ }^{119}$

113. Ibíd., pp. 56, 57 y 65 .

114. Ibíd., p. 62.

115. WalthER. Eigenverantwortlichkeit, cit., pp. 79 y ss.

116. Ibíd., pp. 79 y 80; cfr. Roso. Autoría, cit., p. 191.

117. Ibíd., pp. 80 y 81.

118. Ibíd., pp. 88 y ss. Un mayor desarrollo de la posición de esta autora se puede ver en Cancio. Conducta de la víctima, cit., pp 202 y ss.; García Állvarez. Puesta en peligro, cit., pp. 347 y ss.; Roso. Autoría, cit., pp. 191 y ss.

119. Víctima, cit., pp. 101 y 102. 
-ya advertí que no había tampoco consenso terminológico- en el que "se proyectan los valores de la comunidad jurídica, entre los que ocupa un lugar destacado el principio de libre determinación de la persona"120. Pues bien, este principio se llena de contenido, según TAMARIT, a través de la delimitación de ámbitos de responsabilidad, operación que se desarrolla en la categoría dogmática de la imputación objetiva, lo que "dota de un contenido garantista a la parte objetiva del tipo de injusto [...] de modo análogo a lo que sucede con el principio de culpabilidad (o de imputación subjetiva) en la vertiente subjetiva. Con ello se introduce un tercer filtro a la hora de seleccionar los comportamientos individuales que objetivamente interesan al Derecho, una vez comprobada la causalidad y la autoría"121. Ésta es la vía que propone TAMARIT para valorar normativamente la conducta de la víctima dentro del Derecho Penal. Sólo restaría la cuestión más compleja: determinar los criterios de delimitación de ámbitos de responsabilidad de la víctima y que desplazan la responsabilidad de terceros al ser sus conductas atípicas. TAMARIT mantiene que el presupuesto básico de la delimitación es la fijación de las condiciones personales de tal responsabilidad, y para ello "los criterios a seguir no pueden ser distintos de los que se sirve el Derecho Penal cuando establece las condiciones personales determinantes de la responsabilidad del autor, ya sea en el ámbito del tipo de injusto o en la culpabilidad"122. Así, la víctima no será autorresponsable cuando obre bajo un error invencible que no le permita alcanzar una apreciación aproximativa del peligro que genera su propia conducta, cuando sea inimputable u obre bajo estado de necesidad o miedo insuperable ${ }^{123}$.

Cancio Meliá también parte del principio de autorresponsabilidad conformado por la capacidad de autodeterminarse, lo que conllevará como reverso la responsabilidad por actos propios ${ }^{124}$. Este principio y sus consecuencias, aplicadas al ámbito de la víctima, genera lo que CANCIO ha denominado un ámbito de responsabilidad preferente de la víctima ${ }^{125}$. Según este autor, "al titular de los bienes jurídicos personales debe atribuirse una posición especial. Si el sacrificio por parte del propio titular de esos bienes no es reprimido por el Derecho Penal, y las intervenciones de terceros en actividades autolesivas es incriminada de modo excepcional por normas especiales, parece entonces claro, en primer lugar, que queda al albedrío del titular de esos bienes configurar su actividad vital de tal modo que se genere un riesgo para sus propios bienes. En este sentido, será el titular de esos bienes quien debe determinar cómo manejarlos. Como correlato de esa libertad de organización vital arriesgada, sin embargo, será también el titular quien deba asumir de modo preferente los daños que puedan derivar de ella. La especial relación que une al titular con sus bienes también debe manifestarse, entonces, en segundo lugar-cuando junto al titular intervenga un tercero-, en que nadie puede responder antes que el titular de los daños que se puedan

120. Ibíd., p. 103.

121. Ibíd., p. 102.

122. Ibíd., p. 105.

123. Ídem.

124. Conducta de la víctima, cit., pp. 275 y 276.

125. Ibíd., pp. 276 y ss. 
generar. Lo contrario implicaría privar al titular de su libertad de organización, e imponer a los demás un deber de tutela que, al no estar formulado de modo expreso, no existe" 126 . Ahora bien, esa autorresponsabilidad preferente de la víctima no supone, como aclara CANCIO, una desprotección de la víctima, y por ello precisamente también está sujeta a unos límites. La víctima es responsable preferente dentro de su propio ámbito de organización, pero no es responsable exclusiva, por lo que en determinados supuestos será el tercero interviniente el que rompa esa relación de preferencia del titular con sus bienes jurídicos, debiendo ser declarado el único responsable. Cuándo se produce esa inversión de responsabilidades escapa al concepto de autorresponsabilidad, ya que este principio es sólo un punto de partida valorativo, "mientras que el concreto funcionamiento en el sistema jurídico debe ser elaborado con parámetros dogmáticos"127. Por ello, teniendo presente el punto de partida valorativo, que es el papel que desempeña el principio de autorresponsabilidad en la construcción de CANCIO, considera que la delimitación dogmática del ámbito de responsabilidad preferente de la víctima es un problema de tipicidad ${ }^{128}$, más concretamente de imputación objetiva ${ }^{129}$. Así, la regla general será la responsabilidad preferente de la víctima, a no ser que el tercero ocupe una posición especial de garantía ${ }^{130}$ frente a los bienes de la víctima o no exista imputación objetiva ${ }^{131}$ una vez analizada la conducta de la víctima. Pero además, y para terminar su delimitación del principio de autorresponsabilidad desde parámetros dogmáticos, CANCiO sostiene que los límites del principio de responsabilidad preferente de la víctima se encuentran en la instrumentalización de ésta por el autor, es decir, cuando la víctima no sea responsable por concurrir defectos de responsabilidad o defectos cognitivos que colocan en situación de superioridad al autor ${ }^{132}$.

Para FeıJóo, el principio de autorresponsabilidad aplicado a los supuestos en los que intervine la víctima habría que formularlo del siguiente modo: cuando la víctima haya tomado "una decisión libre sobre el inicio del riesgo o la situación de peligro, aunque ésta pierda posteriormente el control por causas imputables sólo a ella misma y no al tercero", se le debe imputar el riesgo sólo a la víctima ${ }^{133}$. "En general, hay que afirmar que una decisión de la 'víctima' consciente de la peligrosidad de lo que asume o que se puede considerar como descuidada con sus propios bienes jurídicos debe tener como consecuencia normativa que el hecho sólo se le puede imputar a ésta, salvo que el Derecho positivo disponga lo contrario con normas especiales (p. ej., el art. 143 C. P.)"134. En este sentido, el principio de autorresponsabilidad sirve para

126. Ibíd., pp. 277 y 278.

127. Ibíd., p. 279.

128. Ibíd., p. 280.

129. Ibíd., pp. 281 y ss.

130. Ibíd., pp. 280, 308 y ss.

131. Ibíd., pp. 280,303 y ss., 315 y ss.

132. Ibíd., pp. 347 y ss.

133. RDPCr 5,2000 , pp. 308 y 309 .

134. Ibíd., p. 309. 
interpretar el alcance del tipo, determinando cuándo una persona que se lesiona es instrumento o responsable de su autolesión ${ }^{135}$.

\section{TOMA DE POSICIÓN: LAS INFLUENCIAS RECÍPROCAS ENTRE LA AUTORÍA Y LA IMPUTACIÓN OBJETIVA}

En primer lugar, intentaré explicar por qué no me convencen determinados aspectos de dos de las argumentaciones dadas por los autores expuestos al inicio de este trabajo. El resto de las construcciones serán valoradas al hilo del desarrollo de mi posición. Después de este primer paso expondré la solución propia.

1. La tesis de MAYOL es la más original y creo que por ello la más arriesgada. Esta solución nos ofrece una nueva perspectiva de exégesis de los criterios de la imputación objetiva, ya que la autora los reinterpreta, como hemos visto, desde los principios, requisitos y límites de la legítima defensa. Pues bien, en mi opinión esta solución es metodológicamente incorrecta, ya que no se puede trasladar toda la teoría de las causas de justificación a la imputación objetiva. En este caso, MAYOL ha recurrido a la legítima defensa, porque ha considerado que, de haberse defendido la víctima atacando los bienes del agresor, hubiera concurrido esta causa de justificación; pero si, por el contrario, hubiera habido una "agresión" imprudente por parte de JOAQUín ${ }^{136}$, ya no se podría aplicar la legítima defensa, sino el estado de necesidad, siempre y cuando la víctima hubiera iniciado una actuación salvadora que recayese en los bienes del "agresor", actuando contra la fuente de peligro (estado de necesidad defensivo), o que recayese en bienes ajenos (estado de necesidad justificante). Si así fuese, ¿habría que interpretar, entonces, la imputación objetiva desde los límites y requisitos del estado de necesidad? En mi opinión, la defensa de la tesis de MAYOL avoca a este planteamiento; y con ello, primero, volveríamos a reducir el concepto de delito a la imputatio iuris y a la imputatio facti; en segundo lugar, se perderían los contornos de la imputación objetiva del resultado y se crearía una macroinstitución producto del forzamiento de cambios sistemáticos ya denunciados por mí y, antes que por mí, por otros autores ${ }^{137}$; y, en tercer lugar, la construcción de MAYOL no se distancia tanto de la del Tribunal Supremo, ya que también éste recurre a analizar en la imputación objetiva principios, como es el de la proporcionalidad entre males, propios de las causas de justificación en la imputación objetiva. Por tanto, ambas soluciones sólo se diferencian por la causa de justificación elegida, pero vuelvo a incidir en el hecho de que ambas causas de justificación serían, recurriendo a la analogía, posiblemente aplicables al caso, ya que si para el Tribunal Supremo hubo, en vez de dolo en JoAQuín, imprudencia consciente -cuestión que no se desarrolla en la sentencia, con lo que la falta de fundamentación sería criticable-, la solución a la que llega el Tribunal Supremo, sería perfectamente sostenible desde las premisas metodológicas utilizadas por MAYOL; con lo que no creo que ya se pueda justificar la crítica a la sentencia

135. Resultado lesivo, cit., p. 346.

136. Cfr. supra nota 25.

137. Cfr. Roso. Autoría, cit., pp. 119 y 121 y pássim. 
por parte de esta autora. En conclusión, ambas construcciones - la de MAYOL y la del Tribunal Supremo- adelantan criterios y requisitos propios de la valoración de la antijuridicidad a la imputación objetiva.

2. CANCIO considera, con la mayoría de los autores que comentan la sentencia, que es un problema de imputación objetiva, pero no de la tradicional imputación objetiva del resultado, sino del primer nivel de la imputación objetiva, la imputación objetiva del comportamiento, que tiene como función delimitar ámbitos de responsabilidad ${ }^{138}$. En el caso de la sentencia, considera que el responsable es Iván, puesto que hay imputación objetiva al cumplirse el requisito de la "organización conjunta", no haber autoría mediata y no tener JOAQUín - el conductor- una posición de garantía con respecto de los bienes jurídicos de Iván. Partiendo de la propia construcción de CANCIO y dejando aparte la cuestión de si comparto su estructura de la imputación objetiva, creo que es discutible la concurrencia de los requisitos de la "organización conjunta" y la falta de instrumentalización. CANCIO afirma la existencia de ambos requisitos que se completan con la negación de la existencia de una posición de garantía en JOAQUín. Consecuentemente, admite la responsabilidad preferente de la víctima y, por tanto, no imputa objetivamente las lesiones a JOAQuín. Pues bien, en cuanto al primero de los requisitos, la "organización conjunta" ${ }^{139}$, considero, al contrario de CANCIO, que no existe. No puede ser inherente a la actividad elegida por la víctima, la de hacer auto-stop, que le roben; ni tampoco constituye un factor de riesgo inevitable de esa concreta actividad $^{140}$, como sí lo es, en el ejemplo elegido por CANCIO, el riesgo de lesión corporal que se puede sufrir si se accede a acompañar a un conductor ebrio ${ }^{141}$.

138. Conducta de la víctima, cit., p. 305.

139. CAncio. Conducta de la víctima, cit., p. 290, define del siguiente modo el concepto de "organización conjunta": "Esta organización conjunta no debe entenderse como una actividad compartida en la que de modo paralelo a la coautoría tanto el autor como la víctima aportan algún elemento de cierta importancia a la ejecución de la actividad. Por el contrario, las aportaciones de autor y víctima [...] pueden ser de muy diverso peso [...] Tampoco es relevante per se en este ámbito [...] cuál sea la interpretación asignada en su fuero interno por autor o víctima al contexto de interacción. Lo importante es que la interacción entre víctima y autor crea un contexto común de un mismo significado objetivo. Este significado objetivo se determina conforme a patrones normativos: sólo aquellos aspectos de la organización son 'conjuntos' (sic) que se presentan como un elemento inherente a la actividad elegida por la víctima, y ello como función de su autonomía. Sólo aquellos factores de riesgo que pueden entenderse como elemento inevitable de la actividad son asumidos en función de la autonomía de la víctima. De modo paralelo al principio de actos propios, nadie puede ser distanciado de los riesgos que implica la realización de la actividad que pone en riesgo sus bienes sin resultar contradictorio y poner en duda, precisamente, su autorresponsabilidad. El criterio decisivo está, por tanto, en determinar hasta qué punto el contacto social en cuestión puede ser definido de modo unilateral por la víctima como inocuo y a partir de qué momento la organización conjunta abandona esa esfera y adquiere una definición objetiva propia que no depende del arbitrio de los intervinientes".

140. Así tampoco existe "organización conjunta" en el siguiente ejemplo que utiliza CANCio. Conducta de la víctima, cit., pp. 291 y 292, para explicar el concepto: si A facilita la conducción a B, que está ebrio, pero no se sube al vehículo y emprende su camino a pie, "siendo atropellado posteriormente por B, que se cruza en su trayecto, e igualmente a consecuencia del estado de ebriedad, parece evidente que el daño sufrido no puede atribuirse a A: en el contexto facilitar a una persona ebria un automóvil" no implica como organización conjunta el riesgo de un atropello.

141. Ibíd., 1998, p. 291. 
Bien es verdad que la víctima podía haber previsto la posibilidad de sufrir algún ataque a sus bienes jurídicos, pues la experiencia nos dice que la práctica del autostop se ha tornado en una conducta peligrosa, pero el propio CANCIO expone que ello no es suficiente para encontrarnos ante una "organización conjunta" de la actividad peligrosa. Así, no supone una organización conjunta "la mera realización de una actividad que implique meros riesgos estadísticos de sufrir una lesión, por muy altos que éstos sean o aunque la posibilidad de la lesión haya sido concretamente prevista por el sujeto que resulta lesionado. Quien pasea por un bosque en el que sabe que hay muchos cazadores furtivos que no son demasiado cuidadosos en el uso de sus armas de fuego no organiza conjuntamente con éstos una actividad que conlleve el riesgo de muerte por un disparo descuidado. La mujer que sabiéndose atractiva acepta una invitación de un hombre que tiene fama de violento no organiza conjuntamente con éste una actividad que implique el riesgo de algún tipo de ataque contra la libertad sexual. Pues en estos casos -aunque la víctima prevea la posible lesión-, el potencial lesivo que comportan las distintas actividades no puede ser atribuido a la conducta de la víctima: ésta queda distanciada de aquel, pues desde el punto de vista normativo las conductas referidas no implican la asunción del riesgo en cuestión"142. Dicho esto, me pregunto qué diferencia ve CANCIO entre el segundo supuesto del auto-stop y los ejemplos propuestos por él mismo, para negar en éstos la organización conjunta y afirmarla en aquél ${ }^{143}$. En mi opinión, no hay ninguna, porque en ninguno de los dos casos hay asunción del riesgo por parte de las víctimas ${ }^{144}$, y consecuentemente habría que negar que la víctima sea autorresponsable e imputar objetivamente las lesiones a JOAQUín.

Pero, siguiendo con los requisitos que CANCIO enumera, considero que en este caso existe una relación de instrumentalización que fundamenta la autoría mediata; al contrario que CANCIO, que niega esta relación basándose en dos razones, como ya expuse en su momento y que vuelvo a recordar: 1 . El criterio de la racionabilidad desde la perspectiva de la víctima de que se vaya a producir un posterior daño, y 2. La inviabilidad de aplicación de un análisis analógico del estado de necesidad disculpante, ya que "mientras en el caso del camión antes citado [...] la apariencia de la próxima comisión de un delito contra la libertad sexual hacía presentarse al salto del camión como una reacción forzada por la situación impuesta por el autor, en este supuesto la posibilidad de un delito contra la propiedad -puesto que no existían indicios de que fuera a cometerse otro distinto, es más, la navaja no apareció físicamente en ningún momento- no hace aparecer el peligroso salto como una reacción forzada"145. En este punto vuelvo a

142. Ibíd., p. 292.

143. En este mismo sentido, BACIGALUPO, en $R D P P$ 2, 2000, p. 185, expone que "ciertamente sería posible sostener que en el caso de la sentencia la acción del acusado queda fuera de la organización conjunta, pues, si yo entiendo bien, lo único conjuntamente organizado es el transporte del otro. No parece que el robo pueda ser una ‘organización conjunta' del ladrón y de la víctima”.

144. Con toda la razón, GARCÍA ÁlVAREZ, en RDPCr 3, 1999, p. 410, manifiesta que la asunción del riesgo implica conocimiento y voluntad, "luego, en definitiva, la teoría de CANCIO sólo es aplicable a las conductas de riesgo en las que el titular del bien jurídico interviene (junto a un tercero) con conocimiento del riesgo y de manera voluntaria".

145. $R D P P 2,2000$, p. 173. 
cuestionarme los aspectos distintivos que maneja CANCIO en su argumentación, entre el primer caso y el segundo caso del auto-stop, pues creo que no existen tales diferencias. Tampoco en el caso del camión el sujeto activo hace ademán alguno de forzar a la víctima, simplemente le hace proposiciones sexuales -nadie podría asegurar que el camionero quería realmente consumar la relación, podría estar jugando gastándole una broma-; es decir, lo que defiendo es que el nivel de apariencia de la próxima comisión de un delito es, en mi opinión, el mismo en ambos casos ${ }^{146}$.

3. Pasando ya a la solución propia, a. Considero, como toda la doctrina, que el caso que nos ocupa plantea problemas en el tipo, y en concreto en el tipo objetivo ${ }^{147}$. Sin embargo, al contrario de la opinión mayoritaria, no creo que los supuestos de autopuestas en peligro, ya sea la intervención de la víctima anterior, simultánea o posterior a la del tercero, se solucionen sólo con la aplicación de los criterios de la autoría o sólo con las reglas de la imputación objetiva ${ }^{148}$, se le dé a esta última institución el contenido que se quiera. Más bien, como he dicho al inicio, el problema es de tipo y afecta a todo el tipo objetivo, y sólo con una aplicación e interpretación integradora de las categorías dogmáticas que lo delimitan podremos llegar a solucionar estos casos de modo satisfactorio. Esta ubicación dogmática del problema se pone aún más de manifiesto en el supuesto concreto objeto de este comentario, pues, aunque pertenece o se puede englobar dentro de lo que se ha denominado "autopuestas en peligro", estos casos plantean una especialidad frente a los demás: la autopuesta en peligro es la vía de salvación que ha elegido la víctima para protegerse de la "agresión” del tercero. En otras palabras, lo que genera la autopuesta en peligro es la existencia anterior de una puesta en peligro de sus bienes jurídicos por un tercero, y la autopuesta en peligro se presenta como la vía de escape a una lesión segura ${ }^{149}$, al

146. En mi opinión, CANCiO debería haber llegado con la aplicación de su construcción a defender la misma solución en ambos supuestos del auto-stop.

147. Sin olvidar los problemas que también se pueden plantear en la parte subjetiva en estos supuestos, debidos a la delimitación entre la imprudencia consciente y el dolo eventual. Ahora bien, podemos encontrarnos ante un supuesto en que por sus características no sea posible hablar ni de dolo ni de imprudencia, por ser de todo punto imprevisible la concreta manera de autoprotección autolesiva realizada por la víctima, con lo que, como es lógico, ya no existiría la necesidad de analizar la parte objetiva.

148. Esta hipótesis de trabajo encuentra el refrendo suficiente en los propios autores que han intentado encontrar la solución en la imputación objetiva, ya que de un modo o de otro han tenido que hacer referencia a la autoría para delimitar sus construcciones. Así, entre otros, ZACZYK. Selbstverantwortung, cit., pp. 61 y s.; CANCIO. Conducta de la víctima, cit., p. 347, que considera la autoría mediata como un límite a la imputación a la víctima.

149. Los casos de autopuestas en peligro pueden adoptar desde una perspectiva fáctica-naturalista distintas formas de organización o de estructura: en ocasiones la víctima no lleva a cabo actos ejecutivos (piénsese en el suicidio o en el homicidio consentido), y en otras la víctima lleva a cabo actos ejecutivos, que pueden ser anteriores, simultáneos y posteriores a los del tercero (cfr. CANCIO. Ob. cit., pp. 22 y ss.). Ahora bien, los supuestos que se tratan en este trabajo presentan una especificidad que no poseen todos los anteriores: el tercero que actúa en primer lugar crea un riesgo para bienes jurídicos de la víctima; en el resto de supuestos ello no es así: el riesgo comienza en el momento en que la víctima da su consentimiento o actúa. En mi opinión, ello justifica la necesidad de crear un subgrupo dentro del concepto global de autopuestas en peligro, con el objeto de determinar las 
menos desde la perspectiva de la víctima. Con lo que ya, en su origen, parece que existe una situación de autopuesta en peligro forzada, que obliga, en mi opinión, a un determinado orden de análisis metodológico: en primer lugar, habría que descartar esa impresión inicial de coacción o amenaza que puede estar sufriendo la víctima o, por el contrario, reafirmarla, analizando, entonces, la existencia (o no) de una relación de instrumentación basada en la coacción que pueda justificar la aplicación de una autoría mediata. Una vez que se llega a la conclusión que en el caso concreto hay un autor mediato y un instrumento, se plantea el análisis de la imputación objetiva, pasando de este modo a discutir cómo afecta la concreta forma de autoría utilizada a la imputación objetiva.

b. Comenzando por el estudio de la autoría en estos supuestos, el análisis se centra en la figura de la autoría mediata ${ }^{150} \mathrm{y}$, para ello, debemos volver a la cuestión, planteada al principio, de cuándo la situación coactiva tiene la entidad suficiente para fundamentar una relación de instrumentalización, en que se rompa con el esquema lógico y habitual del orden de intervención, en donde el último interviniente suele ser el que determina objetiva y positivamente el hecho ${ }^{151}$. En mi opinión, siguiendo una concepción normativa, la autoría mediata a través de la coacción existiría cuando la víctima se encuentre en una situación análoga -pues elige entre la puesta en peligro de varios bienes jurídicos, pero siempre propios-al estado de necesidad justificante, pero también cuando exista una situación de inexigibilidad o inimputabilidad y ello anule la posibilidad de considerarle un sujeto autorresponsable ${ }^{152}$. Es decir, de lo que se trata es de que la coacción ejercida cree un supuesto de irresponsabilidad o responsabilidad disminuida reconocido por el propio ordenamiento jurídico penal. Por tanto, comparto las tesis normativas, que defiende la doctrina alemana, basadas en la idea de que debe ser el ordenamiento el que marque los límites de capacidad de resistencia, como decía Roxin, ante una coacción, pero teniendo siempre presente la regulación española. Y en este punto, siguiendo la tesis de GARcía ÁlvAREZ, he optado por una postura amplia.

c. Ahora bien, en la aplicación analógica del estado de necesidad justificante se ha introducido por JAKOBS un criterio corrector como es el de la racionalidad. Con este criterio se intenta flexibilizar el requisito de la proporcionalidad entre los males exi-

características especiales y comunes de estos supuestos y de definir los criterios de autoría y de imputación objetiva que hay que aplicar a las autopuestas en peligro autodefensivas.

150. También se podría dar la figura de la coautoría entre el tercero y la víctima que codeterminan o codominan, según si es una autopuesta en peligro imprudente o dolosa, el hecho. Las soluciones a este supuesto serían distintas atendiendo a las construcciones defendidas por la doctrina e irían desde la punibilidad de la conducta del tercero-coautor hasta su no punición si se piensa en el principio de responsabilidad preferente de la víctima defendido por CANCIO. Cfr. sobre esta cuestión, entre otros, Hernández Plasencia. Autoría mediata, cit., pp. 232 y ss.

151. Cfr. Roso. Autoría, cit., p. 544.

152. Recientemente, llegando al mismo resultado, como ya se pudo concluir supra de la exposición de sus argumentos, que el que aquí ya se defendía, González Cussac y Mira Benavent, en L-H Cerezo, 2002, pp. 729 y ss. 
gido en el estado de necesidad justificante, pues la rigidez de tal principio tiene su razón de ser en que los bienes que se lesionan con la acción salvadora pertenecen a un tercero completamente ajeno a la situación de necesidad; sin embargo, en estos casos la víctima, que es siempre la que realiza la acción salvadora, es la titular de todos los bienes jurídicos que se ponen en peligro y, por consiguiente, la elección de cuál bien salvar se circunscribe a sus propios bienes, con lo que la víctima puede reorganizar sus bienes como quiera, siempre que la decisión no sea irracional y obtenga algún tipo de ventaja. Pues bien, este argumento me parece perfectamente sostenible ${ }^{153}$, pese a las críticas recibidas en cuanto al grado de concreción ${ }^{154}$ de la racionalidad, puesto que ello no supone más que un esfuerzo interpretativo, que se puede guiar y ayudar por los criterios empleados para emitir el juicio de proporcionalidad entre los males en el estado de necesidad defensivo, en el que se modifica la ponderación de intereses, precisamente porque se actúa frente a la fuente de peligro, y se permite causar un mal mayor que el que se trata de evitar, flexibilizando de este modo el requisito ${ }^{155}$. Con lo que no estoy de acuerdo es con el lugar sistemático en el que la sentencia ha colocado el análisis de la proporcionalidad y que algunos de los autores expuestos alaban ${ }^{156}$. La proporcionalidad entre los males y su correctivo: la racionalidad, en el caso de que el tercero afectado por la coacción o la amenaza sea la víctima, es una cuestión de antijuridicidad, no de imputación objetiva; y que se adelante su discusión en algunas ocasiones al tipo por exigencias conceptuales de otras categorías dogmáticas, como pasa en este caso concreto al tener que construir la relación de instrumentación para afirmar la autoría mediata, no le hace perder su naturaleza. Esto no quiere decir que conciba cada categoría del delito aislada de las demás -lo que pecaría de ingenuidad, además de constituir un error metodológico- sino que considero que hay determinadas instituciones, conceptos o criterios que han sido elaborados para medir la contrariedad a Derecho y otros para establecer la tipicidad de la conducta. Si ello es así, la proporcionalidad no está hecha para decirnos si la conducta del que se defiende es típica o atípica, sino para dar contenido a la norma de valoración a través de un juicio de medición del injusto. Es decir, la proporcionalidad nos informa de si la actuación del que se defiende ha creado males mayores, iguales o inferiores a los que trataba de evitar. Y es que el injusto es una categoría graduable, la tipicidad no ${ }^{157}$.

Por tanto, si no hay proporcionalidad entre los males, faltará un estado de necesidad justificante completo y habrá responsabilidad penal del instrumento en los casos nor-

153. No estoy de acuerdo con la interpretación que TAMARIT, en RDPP 2, 2000, p. 181, da al concepto de racionalidad, ya que considera que lo decisivo es "el carácter inminente o remoto del peligro que para los bienes jurídicos suponen la agresión y la reacción”. Ello se puede tener en cuenta como un elemento de valoración más dentro del juicio de racionalidad, pero no puede ser el único.

154. CANCIO. Conducta de la víctima, cit., p. 362.

155. Cfr. Luzón Peña. Curso PG I, cit., p. 633.

156. Cfr. supra la exposición de la posición de TAMARIT.

157. Y por la misma razón, pero a la inversa, tampoco se puede acudir, como sostiene MAYOL, a los requisitos de la legítima defensa para afirmar o negar la imputación objetiva. 
males de lesión de un bien jurídico ajeno, y seguirá habiendo atipicidad en los supuestos excepcionales en los que la víctima se pone en peligro para salvarse del peligro generado por el sujeto de atrás. Sin embargo, ello puede tener alguna trascendencia en la relación de instrumentación, puesto que si la desproporción entre los males ha sido tan grande que se pueda hablar de "exceso" del instrumento es posible que ya no estemos ante un caso de autoría mediata y la conducta del sujeto de atrás, cuando el sujeto de adelante sea la víctima, sea atípica. En otras palabras, si el sujeto de atrás ha organizado la relación de instrumentación con base en un estado de necesidad justificante y el sujeto de adelante lleva a cabo una actuación completamente desproporcionada no habrá relación de instrumentación. Por último, he de advertir que el criterio de la proporcionalidad entre males sólo se aplica a los casos en los que la relación de instrumentación se basa en una coacción o amenaza fundamentada en un estado de necesidad justificante, pero no se tendrá en cuenta si la coacción o amenaza produce un estado de inexigibilidad subjetiva o de inimputabilidad. En tal caso habrá siempre autoría mediata del sujeto de atrás basada en la instrumentalización del sujeto de delante.

d. Otra de las cuestiones que se ha planteado anteriormente es el alcance, naturaleza y contenido del principio de autorresponsabilidad. Como se pudo observar, no existe una posición unánime sobre su contenido y naturaleza: en cuanto a su naturaleza, unos lo consideran un concepto prejurídico, otros un principio rector, algunos un principio valorativo; si la cuestión se centra en darle contenido a través de las categorías dogmáticas, la ubicación sistemática tampoco es homogénea. En mi opinión y como ya tuve oportunidad de exponer en un trabajo anterior ${ }^{158}$, el principio de autorresponsabilidad es un principio rector e informador del sistema y, por tanto, limitador del ius puniendi, que no aporta ningún criterio material para delimitar responsabilidades y que se introduce teniendo en cuenta valores inherentes a la personalidad como la libertad, la autonomía o la autodeterminación. Por tanto, siguiendo a CANCIO, introduce un punto de partida valorativo en el sistema y su funcionamiento dentro de éste se realiza, como pasa con otros principios, a través de construcciones dogmáticas, las cuales sí pueden ser criticadas, pero no la validez del principio. En efecto, desde la óptica normativa se le ha dado dos enfoques a la autorresponsabilidad, uno ontológico-psicológico y otro normativo. Ambos sirven para interpretar la relación de instrumentación en la autoría mediata. Así, desde una perspectiva ontológicopsicológica el sujeto de adelante tiene que ser un sujeto libre, con decisiones voluntarias propias y, por tanto, dueño de sus actos, o, por decirlo de otra manera, recurriendo a categorías propias de la culpabilidad, debe tratarse de un sujeto completamente imputable dotado de normalidad motivacional, ya que de lo contrario la falta de libertad o de capacidad de elección o decisión en el sujeto de adelante le convierte en un sujeto apto para la instrumentalización por un tercero. Pero se podría mantener que esta acepción fáctico-psicológica del principio sólo tiene virtud declarativa, a la que hay que llenar de contenido, y ello sólo puede conseguirse a través del análisis jurídi-

158. Autoría, cit., p. 204. 
co-normativo del principio ${ }^{159}$. Por ello, se recurre a criterios de naturaleza normativa para establecer el dominio o determinación del hecho por medio de la coacción y, por ende, la existencia o inexistencia de autorresponsabilidad del sujeto de adelante. No obstante, quiero advertir que con esta relación que he establecido entre autoría mediata y principio de autorresponsabilidad no persigo en absoluto dar a entender que este principio es una idea rectora privativa de esta categoría dogmática; muy por el contrario, creo que como principio debe influir e impregnar todo el edificio dogmático, por lo que también estará presente en la imputación objetiva, en la comisión por omisión, en la culpabilidad, etc.

e. Para terminar con la autoría mediata y a modo de recapitulación, considero que deben concurrir los siguientes requisitos: i. Una relación de instrumentación "que implique una subordinación del sujeto de delante frente al sujeto de atrás, originado normalmente por una carencia o un déficit existente en la conformación del hecho propio"160; ii. El sujeto de atrás ${ }^{161}$ debe crear o aprovecharse de la situación de nece-

159. También en esta categoría del tipo, pese a tenerse más en cuenta esa vertiente psicológica del principio debido al estudio de la relación de instrumentalización y de la autorresponsabilidad del instrumento, el principio sufre una valoración teleológica y tiende a normativizarse. Y es que ambas acepciones del principio para nada son incompatibles, sino que se pueden presentar unidas y una ser la consecuencia de la otra, ya que cuando el sujeto es capaz de ser responsable, es cuando se le puede atribuir lo realizado por él y no por otro, y ello plantea la exigencia normativa de delimitar ámbitos de responsabilidad. Desde esta perspectiva, que se acaba de apuntar, BolEA BARDón. Autoría mediata, cit., pp. 117 y 118, considera el principio de propia responsabilidad como una premisa axiológica de su construcción del concepto de autor y por tanto del autor mediato, definiéndolo a través de tres facetas fundamentales: "En primer lugar, constituye el reverso (corolario) del principio de autonomía individual, que impone la separación entre esferas organizativas autónomas. En segundo lugar, derivado de lo anterior, impone una delimitación entre esferas de responsabilidad. Y, en tercer lugar, fundamenta la responsabilidad en la propia conducta, estableciendo así un límite general a la atribución de responsabilidad (pues no permite castigar por conductas ajenas)". Dicho esto, BoLEA mantiene que una persona será responsable por los riesgos que crea dentro de su propia esfera de organización y cree que esta idea debe estar muy presente entre la distinción de formas de intervención en un hecho y en todas las formas de intervención, pues cada uno sólo es responsable de lo realizado por él mismo y no por las consecuencias derivadas de una conducta ajena.

160. Roso. Autoría, cit., p. 550.

Para algunos autores la autoría mediata no sólo cabría cuando el sujeto de adelante fuera absolutamente irresponsable desde una perspectiva jurídico-penal, sino también cuando el instrumento fuese un instrumento "cuasi-responsable", con lo que admiten la figura del autor detrás del autor. Ello, como se puede advertir, afecta a la forma de entender la suficiencia o aptitud de la coacción para justificar el dominio o la determinación sobre el hecho, ya que lo que hay que constatar, como expone Hernández Plasencia. Autoría mediata, cit., p. 162, es si se reconoce una instrumentalización fáctica con relevancia en el campo normativo, y ello no sólo ocurre cuando el instrumento es irresponsable jurídico-penalmente. Así, considera que para que haya dominio del hecho por el autor mediato la violencia o coacción se debe ejercer en fase de resolución y de ejecución, por lo que la resolución y la ejecución deben ser no libres. "El dominio del hecho, como dominio sobre la cualidad lesiva de la acción, se cifraría entonces en controlar y restringir de forma inmediata la acción del instrumento; la inmediatez del control no se identifica, sin embargo, con una inmediatez temporal, en el sentido de que deba controlar el autor mediato al instrumento en el momento en que éste ejecuta el delito, sino que la coacción determina de manera directa la afectación a la libertad de decisión del ejecutor, de forma que no le deja otra opción que la de sufrir un mal o causar la lesión al bien jurídico" (p. 162). Por ello, concluye este autor "que la imagen normativa de la 
sidad o de miedo insuperable que sufre el instrumento y dominar o determinar el hecho; iii. Pero, además, el sujeto de adelante debe realizar la acción más idónea y más apta para la producción del resultado; de este modo el sujeto de atrás domina de manera mediata, pero directa, ya que maneja, a través de la relación de instrumentación del sujeto de adelante, la creación de la acción arriesgada o del riesgo que tiene como cualidad intrínseca la producción irremediable del resultado con sus circunstancias concretas e irrepetibles ${ }^{162}$.

Por consiguiente, volviendo al caso de la sentencia comentada, en mi opinión hay autoría mediata, debido a la existencia de coacción bastante creada por el sujeto de atrás, que da lugar a la falta de voluntad libre del instrumento ${ }^{163}$. Esta situación no está originada solamente por una sola de las actuaciones de JOAQUín, como ya lo ponían de manifiesto con toda la razón MAYOL ${ }^{164}$, BoNET ${ }^{165}$ y GARCÍA ÁllvAREZ ${ }^{166}$, por lo que, en mi opinión, constituye un error metodológico en este caso concreto aislar una de las conductas sin tener en cuenta el conjunto de circunstancias que configuran

instrumentalización no se corresponde únicamente con los supuestos en que el Derecho libera de responsabilidad al que actúa delante, sino también cuando actúa culpablemente con responsabilidad atenuada. Por tanto, la falta de libertad en el dominio a través de la coacción se corresponde con que la instrumentalización fáctica alcance un reconocimiento en la plasmación de un déficit de libertad reconocido por el Derecho, porque éste reconoce también una responsabilidad atenuada" (p. 164). En sentido similar, Bolea BARdón. Autoría mediata, cit., pp. 158 y ss., admite la figura del autor detrás del autor y afirma que esta admisión no es incompatible con la existencia del principio de responsabilidad (pp. 161 y 162), el cual no se puede entender como criterio fundamentador de la autoría mediata (pp. 157 y 158). "El fundamento específico de la autoría mediata en sentido estricto hay que buscarlo en la intervención en ciertas condiciones en un hecho, respecto al cual nadie más va a decidir de forma autónoma" (pp. 159 y 160). Ahora bien, "para poder afirmar la autoría del hombre de detrás, una vez confirmada la plena responsabilidad del autor inmediato, es necesario constatar una manipulación de la situación que permita al hombre de detrás contar con la lesión o puesta en peligro del bien jurídico, a pesar de que otra persona haya de tomar una decisión autónoma en relación al mismo proceso delictivo. Una manipulación de esta clase normalmente se consigue generando en el autor inmediato un déficit de conocimiento o de libertad, ya sea provocando una situación de necesidad coactiva para otra persona, ya sea manipulando una decisión delictiva ajena en contra de un tercero; o bien provocando un estado de inimputabilidad o un error de prohibición. Pero, en ocasiones, el dominio del riesgo se obtiene sin necesidad de provocar en el autor inmediato ni un defecto de conocimiento ni de libertad. En concreto, me estoy refiriendo a organizaciones que operan al margen de la ley, en las que el hombre de detrás dispone de capacidad para dictar órdenes, pudiendo contar con que las mismas serán cumplidas por los inferiores jerárquicos" (p. 162); CFR. DíAZ y GARCía CONLLEDO, en EPBCOm, 2002, p. 147. En mi opinión, la cuestión es dudosa, pero puede haber algunos casos de autor detrás del autor, sobre todo en supuestos como el que nos ocupa, en los que el instrumento obra en estado de necesidad incompleto o es un semiimputable o el miedo es superable para el instrumento.

161. Con respecto al estudio de la estructura de la autoría mediata y el cambio de enfoque que se produce con la monografía de Roxin, al examinar la conducta del sujeto de atrás, que se había mantenido relegada a un segundo plano, pues el análisis se centraba en los defectos del instrumento, cfr. BolEA Bardón. Autoría mediata, cit., pp. 165 y ss.

162. Roso. Autoría, cit., pp. 532 y ss., 550 y ss.; íD. TSJ y AP Aranzadi 21, 2002, pp. 18 y ss.

163. Cfr. Díaz y García Conlledo. Ob. cit., p. 163.

164. APen 2001, p. 62.

165. $R D P P 2,2000$, p. 165.

166. Ibíd., p. 177. 
la situación global. No se puede tomar como centro de imputación sólo el hecho de intimidar con una navaja que no se ha enseñado, pues ello daría lugar a cercenar la realidad de los hechos y a impedir una valoración jurídico-penal completa de la situación. Por tanto, considero que la situación de presión psicológica la crea JOAQUín por medio, en primer lugar, de la intimidación que en principio va dirigida a la realización de un robo y, en segundo lugar, por medio de su negativa a parar el vehículo, aun sabiendo que Iván estaba asustado, nervioso, había abierto la puerta del vehículo y había hecho ademán de tirarse. En este caso no sólo se atacó el patrimonio y la integridad física de la víctima, sino también su libertad ambulatoria ${ }^{167}$. A Iván, ante ello, sólo le quedan dos alternativas: o contraataca y se defiende de una agresión ilegítima lesionando los bienes jurídicos del agresor, o huye poniendo bienes jurídicos propios en peligro. Como se ve, queda patente que la capacidad de elección de la víctima queda coartada, y ello conduce a crear una relación de instrumentalización ${ }^{168}$ y un dominio de la situación por el sujeto de atrás, generada en un principio por una situación análoga a un estado de necesidad justificante, pero que por el curso de los acontecimientos se tornó en una situación de inexigibilidad subjetiva, en la que es difícil aplicar el criterio de la racionalidad sobre la disposición de los bienes.

f. Una vez establecida la relación de autoría, habría que analizar la imputación objetiva. Mi propuesta en estos casos, como he comenzado diciendo al principio de este primer punto de conclusiones y he dejado entrever a lo largo de este trabajo, es analizar la imputación objetiva sin perder de vista las conclusiones a las que se ha podido llegar en el estudio de la autoría ${ }^{169}$. Creo que de este modo tal vez se puede llegar a la

167. En el mismo sentido, González Cussac y Mira Benavent, en L-H Cerezo, 2002, pp. 728 y 729, que critican, igualmente, la sentencia en este punto y manifiestan que el Tribunal Supremo al realizar dicha ponderación olvida al menos tres cosas: "que el delito de robo con intimidación que padeció la víctima es un delito pluriofensivo en el que, al margen de la propiedad, se lesionan otros bienes jurídicos de carácter personal que el legislador también valora, pues precisamente en este delito la víctima entrega lo que vale menos (la cartera o el reloj) para intentar salvar lo que vale más (esos otros bienes personales, entre ellos la integridad física, que pueden verse afectados o puestos en peligro por la intimidación); que tratándose en este caso de una tentativa de robo con intimidación, la propiedad no se lesionó efectivamente (sólo se puso en peligro), pero sí se lesionaron o pusieron en peligro de forma efectiva esos otros bienes personales (entre ellos la integridad física de la víctima) como consecuencia del uso de la intimidación; y que, además de lo dicho, también se lesionó en este caso la libertad de movimientos de la víctima, que insistente e infructuosamente había solicitado al autor que detuviera el vehículo y que la dejara marchar".

168. Para que exista una relación de instrumentalización no hace falta llegar a la supresión de toda alternativa posible de elección, sino que basta con limitar de manera relevante las posibles alternativas de elección. Cfr. Bolea Bardon. Autoría mediata, cit., pp. 288 y ss., que considera estos supuestos comprendidos dentro de la figura del autor detrás del autor, en los que existe un dominio compartido del riesgo.

169. Ello no quiere decir, siguiendo a LuZÓn PEÑA, en DPCir, 2. ㄹ ed., cit., p. 96, que considere que el análisis de la autoría deba ser anterior en cualquier caso al de la imputación objetiva, sino que esta cuestión dependerá de las características del supuesto concreto y del ahorro analítico que arroje la valoración de cada una de las categorías; pues de lo que se trata, a fin de cuentas, es de evitar el análisis pormenorizado de ambas, si ya en una de ellas salta a la vista la falta de algún componente o requisito que conduce inevitablemente a la solución de la impunidad por falta de tipicidad objetiva. Sobre esta cuestión, de modo más desarrollado, cfr. Roso. Autoría, cit., pp. 533 y ss. 
solución correcta, y veamos por qué: i. Con el análisis de la autoría conseguimos saber quién determina o domina el hecho: si la víctima o el tercero; en el caso de que sea la víctima, se consigue automáticamente convertir al tercero en partícipe, y ello significa de inmediato la falta de responsabilidad penal acudiendo al argumento de la participación en el hecho principal atípico; y ii. Si analizamos la imputación objetiva sin tener en cuenta el análisis de la autoría en este grupo de casos y en concreto en el de la sentencia, probablemente se niegue su existencia, como de hecho ha ocurrido.

Pasemos al análisis de los requisitos de la imputación objetiva. En primer lugar, podría plantear problemas la previsibilidad o la pretendibilidad objetiva de la acción, puesto que podría mantenerse que es poco probable o, en cualquier caso, discutible que a alguien que se le pide un reloj intimidándole con una navaja, que ni siquiera se enseña, vaya a terminar tirándose de un vehículo en marcha, incluso si la víctima manifiesta su intención de tirarse del vehículo en marcha si el conductor no para. El hombre medio ideal podría pensar que simplemente es una amenaza de la víctima que en ningún caso va a cumplir o que la probabilidad de que alguien se tire por esas razones es muy baja. Sin embargo, el juicio de previsibilidad cambia si se ha afirmado en el análisis anterior de la autoría mediata que hay una relación de instrumentación basada en una coacción, puesto que sí es previsible que una persona coaccionada o amenazada opte por tirarse de un vehículo para liberarse de una situación de presión o de miedo. En segundo lugar, en cuanto a la relación de riesgo, habría que plantearse si los riesgos generados con la forma concreta con la que se ha llevado a cabo la instrumentación del sujeto de adelante son los que se han cumplido en el resultado, y es que, como vengo sosteniendo con una parte de la doctrina, la imputación objetiva tiene que tener en cuenta la forma concreta en la que se ha conformado la autoría y, en su caso, la participación ${ }^{170}$. En este caso, la coacción o la amenaza crea el riesgo que se produce en el resultado concreto: si a un sujeto se le amenaza con la existencia de una navaja y se le priva de su libertad ambulatoria, no parando el coche y no dejándole bajar, y se ha comprobado en el análisis de la autoría que ello ha sido suficiente para crear, por las circunstancias del caso concreto, una situación de coacción que fundamenta una relación de instrumentalización, entonces también se está creando una situación de riesgo que es la que efectivamente ha generado la realización de ese preciso resultado, ya que la coacción, en la forma concreta en la que se produce, implica una respuesta irracional del sujeto amenazado, como es la de tirarse de un coche por el mero robo de un reloj. En otras palabras, la presión a la que se somete a la víctima lleva inherente la creación de una idea obsesiva -y, por tanto, no fríamente meditada- en ésta: la de escapar de la situación amenazadora, y éste es precisamente el riesgo que se cumple en el resultado concreto, es decir, "el riesgo típico que de suyo implica tal acción"171. Sin embargo, habría que negar la relación

170. Gómez Rivero. La inducción a cometer el delito, Valencia, Tirant lo Blanch, 1995, pp. y 71 ss., 322 y ss; López Peregrên. La complicidad en el delito, Valencia, Tirant lo Blanch, 1997, pp. 233 y ss.; García Álvarez. Puesta en peligro, cit., pp. 356 y 357.

171. Luzón Peña. Curso PG I, cit., p. 383. 
de riesgo si la coacción no hubiera estado dotada de la entidad suficiente para fundamentar una relación de instrumentalización, porque entonces el robo de un reloj por medio de una navaja, de cuya existencia se informa pero no se enseña, a un sujeto al que no se le logra intimidar, no lleva inherente el riesgo de producción de un resultado, como es el de lesiones producidas al arrojarse de un coche en marcha por intentar huir de una situación que no ha constituido ninguna amenaza para este sujeto pasivo.

g. Hasta aquí se ha analizado la adecuación y la relación de riesgo, pero quedaría un tercer criterio o nivel de imputación objetiva, en el que, por cierto, algún autor ha ubicado específicamente la institución de la autopuesta en peligro ${ }^{172}$; me estoy refiriendo al criterio del fin de protección de la norma o alcance del tipo ${ }^{173}$. En este sentido, considero igualmente que, al realizar la interpretación del tipo de la parte especial o el alcance de la norma en el caso concreto, se deben tener en cuenta las conclusiones a las que se ha llegado en el análisis de la autoría. No obstante, recordemos que el propio ponente de la sentencia y algunos de los comentaristas han negado la imputación objetiva precisamente por la no concurrencia de este criterio, al introducir un nuevo juicio de valoración: la proporcionalidad entre los bienes. Por esta vía han conseguido fundamentar la entrada de un nuevo riesgo introducido por IváN, al comparar en su juicio de proporcionalidad el peligro creado por la agresión ilegítima de JoAQuín y el peligro creado por la víctima al intentar escapar de esa lesión. Pues bien, en primer lugar, ese peligro, sea o no sea un nuevo riesgo, no ha sido creado de manera voluntaria y libre por la propia víctima, sino que se debe a la presión motivadora a la que estaba sometida. En segundo lugar, no se trata de un nuevo riesgo, sino que éste es creado por la actuación de JoAquín. En tercer lugar, en mi opinión, como he argumentado en el punto quinto, no se debe utilizar en la imputación objetiva la proporcionalidad en estos términos. Ello será una cuestión que pertenece a la

172. Así, entre otros, Roxin. Problemas básicos del Derecho Penal, Luzón Peña (trad.), Madrid, Edit. Reus, 1976; ÍD. AT, $3^{\underline{a}}$ ed., cit., pp. 335 y ss.; íD. $P G$, 2.ㄹ ed., cit., pp. 387 y ss. introduce estos casos en el criterio del alcance del tipo, en el que está igualmente inmanente la búsqueda del fin de protección de la norma.

173. Aunque ambas expresiones no se refieren exactamente a lo mismo, según aclara Roxin, ya que en un principio su propia construcción contribuyó a crear un estado de confusión, cfr. GARcía Álvarez. Puesta en peligro, cit., pp. 328 y ss., 329 n. 37; FeIóo, en RDPCr 5, 2000, pp. 329 y ss., 329, n. 162; ÍD. $A T$, 3.․ ed., cit., pp. 326 y 327; ÍD. PG, cit., pp. 378 y 379: "Sólo hay que ser consciente de que en la realización del riesgo no permitido se trata siempre del fin de protección de la norma de cuidado limitadora del riesgo permitido (del mandato de iluminación, del deber de consultar a un médico especialista, etc.), y no del fin de protección del tipo penal. En cambio, los casos propiamente dichos de exclusión de la imputación por el fin de protección del tipo son aquellos en que la norma típica (la prohibición de matar, lesionar, dañar, etc.) no abarca de antemano determinadas conductas y consecuencias. Estos supuestos se discuten aquí desde la perspectiva del 'alcance del tipo' [...], y, contra lo que mayoritariamente se hace, no deberían mezclarse con los casos en los que la imputación se excluye ya porque el fin de protección de los mandatos de cuidado no cubre el resultado producido". Con respecto al criterio del "alcance del tipo" y el tratamiento, contenido y su posible autonomía frente a otros criterios que conforman el juicio de imputación objetiva en la construcción de varios autores, cfr. la exposición reciente de Anarte Borrallo. Causalidad e imputación objetiva. Estructura, relaciones y perspectivas, Huelva, Universidad de Huelva, 2002, pp. 281 y ss. 
antijuridicidad y a la teoría de las causas de justificación, pues se está hablando de proporcionalidad entre males, no de imputación de riesgos, y ello no tiene nada que ver con la imputación objetiva. Por consiguiente, no estoy de acuerdo con esta argumentación para negar la imputación objetiva.

En mi opinión, la norma que tiene como fin proteger determinados bienes jurídicos de determinados modos de ataque no puede llegar a la misma solución si existe una relación de instrumentación por coacción que si no existe. Sería evidente que si no hay amenaza o coacción por parte de JoAQuín, la imputación objetiva se negaría; sin embargo, si se piensa en la existencia de una instrumentación, en el caso concreto a través de la coacción, la negación del último requisito de la imputación objetiva es, al menos, discutible. Así, a modo de ejemplo, se pone de manifiesto en una de las sentencias que al principio de este trabajo mencioné, me refiero al caso de la "reacción de pánico", en el que la víctima sale despavorida a avisar a su amiga de lo sucedido y al cruzar la carretera es atropellada por otro conductor ${ }^{174}$. En este caso, SILVA sostiene que no hay imputación objetiva, porque "la norma infringida por M no abarca la evitación de resultados como las lesiones producidas en V. Éstas -como en los casos de daños secundarios por shock- se convierten desde el punto de vista de $\mathrm{M}$ en una casualidad, que habría que considerar excluida del complejo del primer accidente, por mucho que se diera una relación temporal de práctica simultaneidad: M no puede en absoluto "controlar" el proceso que conduce al daño final. En definitiva, la norma infringida (de prudencia en el tráfico) no puede abarcar dentro de su ámbito de protección la evitación de resultados como las lesiones producidas, pues en principio éstas no son algo que ella pueda impedir: también accidentes producidos fortuitamente, con completo respeto de las normas del tráfico, pueden perfectamente dar lugar a reacciones como la de $\mathrm{V}$ y a accidentes como el segundo que se produjo. Éstos, aunque fueran previsibles, no son algo que la norma pueda evitar. De ahí que deba excluirse la imputación objetiva de las lesiones de V a la conducta de M"175. Sin embargo, LuZón PeÑa mantiene la tesis contraria - de modo más convincente por la diferenciación que realiza según la relación de instrumentación o no existente en la actuación de la víctima- una vez que ha admitido la existencia de una autoría mediata imprudente en este caso. Así, expone que, “desde luego, si el móvil de V al emprender la atolondrada carrera en la que se precipita bajo las ruedas del coche hubiera sido exclusivamente la prisa por avisar a la mujer del atropellado, entonces, aparte de que el conductor $\mathrm{C}$ ya no fuera autor de las lesiones, es que el resultado no le sería objetivamente imputable: pues no se puede decir que el fin protector de la norma de cuidado que prohíbe a los vehículos invadir los arcenes, aceras o paseos para peatones sea el evitar que alguno de los presentes pueda salir corriendo a cruzar la calzada sin mirar para avisar a otras personas del incidente, como tampoco se podría decir que las lesiones sufridas por el peatón atolondrado en esas circunstancias supongan la realización precisamente del riesgo o riesgos inherentes a (es decir, que de suyo

174. Cfr. nota 5 .

175. LL 1984-4, pp. 1045 y 1046. 
ésta suele implicar) la acción de invadir el arcén. En cambio, siendo el espanto, terror, conmoción y alteración de ánimo por lo sucedido lo que motiva la ciega carrera y el atropello de $V$, sí que es posible afirmar la concurrencia de imputación objetiva del resultado a la conducta imprudente de $C$ : ya que sí es plausible que uno de los fines que persigue la norma de cuidado que prohíbe a los vehículos invadir aceras o arcenes reservados a peatones sea, no sólo el evitar atropellos directos, sino precisamente el evitar que peatones irrumpan ciegamente en la calzada aterrorizados y alterados por la invasión del vehículo de motor o al ver que arrolla a otras personas $\mathrm{y}$, en consecuencia, también se puede decir que un atropello y lesiones sufridas en esa irrupción de la persona aterrorizada, etc., supone precisamente la realización de uno de los riesgos inherentes a la acción inicial"176.

Las soluciones a las que llegan ambos autores, LuZón y SiLvA, son perfectamente trasladables a la sentencia que nos ocupa, así como sus argumentos. Como ha quedado expuesto, los resultados a los que llegan ambos autores son diametralmente opuestos; sin embargo, me atrevería a mantener que no así sus líneas argumentativas: SiLvA niega la imputación objetiva porque, en primer lugar, el sujeto activo "no puede en absoluto 'controlar' el proceso que conduce al daño final y, en segundo lugar, haciendo una comparación mantiene que los accidentes fortuitos también darían lugar a situaciones de pánico y estos, pese a que sean previsibles, no se pueden evitar por la norma. Empezando por el último de los argumentos, considero que no es pertinente traer a colación los supuestos de caso fortuito, puesto que en ellos ni siquiera se ha creado un riesgo típicamente relevante, es decir ab initio no hay riesgo (no hay ninguna infracción de la norma de cuidado), y no se puede discutir sobre algo que no existe, y mucho menos ya si se abarca o no por la norma. El hecho de que accidentes fortuitos generen una autopuesta en peligro es irrelevante para el Derecho Penal, porque seguimos dentro del ámbito de la casualidad y de lo inopinado y, por ello precisamente, no puede servir de soporte argumentativo para negar el fin de protección de la norma en los casos que están siendo objeto de análisis, en los que sí que se ha creado un riesgo penalmente relevante. En segundo lugar, Silva recurría a la falta de control, para negar que la norma albergarse este tipo de resultados concretos dentro de su ámbito de protección. Justamente la negación de este elemento viene a reconocer y afirmar, subliminalmente en la tesis de SILVA, la necesidad de vincular el análisis previo de la autoría con la imputación objetiva. La idea de control sobre el curso causal pertenece a los criterios y conceptos manejados en la autoría y que curiosamente SiLva utiliza en su argumentación pero sobre la que no profundiza ${ }^{177}$, lo

176. DPCir, 2. ${ }^{\mathrm{a}}$ ed., cit., pp. 100 y 101. Sin cursiva en el original.

177. Considero que la idea de control tal y como la expone SiLva en el texto no es nada clara y puede dar lugar a varias objeciones. En primer lugar, también en el delito doloso el sujeto activo puede, una vez que ha iniciado el curso causal o la acción lesiva, que ha elegido precisamente por considerar que reúne todas las características para producir el concreto resultado, perder el control sobre la acción en aspectos esenciales de su curso causal o inesenciales; en otras palabras y sintetizando el argumento, ningún ser humano controla hasta sus últimas consecuencias la dirección que pueden tomar los acontecimientos. El Derecho Penal se conforma con que el sujeto activo haya elegido la 
que, como he dicho al principio, pone de manifiesto la identidad de argumentos que utilizan tanto Silva como Luzón. Este último autor, al haber seguido un orden de análisis metodológico como el que en este trabajo se propone, llega a la conclusión

realización de una acción que tenga la capacidad y la aptitud suficiente por sí misma para, una vez que la pone en marcha, lesionar el bien jurídico y, pese a ello, se considera que hay control y dominio, aunque el sujeto no tenga jamás un control pleno y exclusivo de los acontecimientos. Así, p. ej., el sujeto que dolosamente dispara una pistola nunca podrá dominar o controlar totalmente el curso de la bala y de los acontecimientos, aunque sea un tirador muy experto y haya apuntado certeramente hacia una dirección; y ello, porque cabe la posibilidad, entre otras, de que se cruce una persona o se interponga un objeto que cambie la trayectoria y el resultado buscado. Cfr. en este sentido LuZón PEÑA, en ADPCP 1989, pp. 894 y 895, en donde expone que el sustrato o base objetiva, es decir el control o determinación del hecho, de la autoría es el mismo para el delito doloso e imprudente, por lo que hay que colegir que tiene las mismas limitaciones en ambos casos; aunque también hace la salvedad (pp. 897 y 898), que comparto totalmente, de que aun siendo la base objetiva la misma se puede ver afectada por la parte subjetiva, ya que al actuar el sujeto con dolo puede hacer frente a los imprevistos y cambios que se presenten en el curso de los acontecimientos, sobre todo en los supuestos en que los cursos causales típicos se prolonguen y no haya una consumación instantánea. cfr. Roso. Autoría, cit., pp. 338 y ss., en donde se expone la concepción de la autoría de LuZÓN PeÑa y las críticas que ha recibido el criterio de la determinación objetiva y positiva del hecho.

En segundo lugar, la idea de control cuando se asocia y se suma a una actuación dolosa se formula en términos positivos, p. ej., el sujeto controla o domina una actuación de matar; sin embargo, la idea de control unida a una actuación imprudente se formula en otros términos: como el sujeto activo no busca en ningún momento el resultado y puesto que el control parece evocar una imagen de cierta consciencia en el sujeto, hay reticencias, incluso idiomáticas, en utilizar la idea de control o dominio, no definiendo el control en términos positivos -por lo que no se dice que el sujeto controla una actuación de matar-, sino en términos negativos a través del criterio de la evitabilidad. De este modo, se formula que el sujeto que no puede evitar de ningún modo la producción del resultado, escapa a su control y pierde el dominio sobre el curso causal. Esta parece que es la concepción que mantiene SILVA, cuando, en el caso de la sentencia que comenta, argumenta que "M. no puede en absoluto 'controlar' el proceso que conduce al daño", por lo que la norma ya no puede pretender evitar la producción del resultado, ni afirmar la imputación objetiva e imponer una pena siempre y cuando se cumplan el resto de elementos del delito-. Pues bien, considero que la idea o criterio de la evitabilidad se puede tener en cuenta en otros elementos del delito, pero no para describir y delimitar la existencia de control o dominio por un sujeto sobre el curso causal. Así, en primer lugar, la evitabilidad serviría para describir las actuaciones imprudentes: un sujeto activo actúa de manera imprudente generando de este modo que el riesgo se descontrole, pudiendo evitar precisamente, si hubiese estado atento al cumplimiento de lo preceptuado por la norma de cuidado, que ello no sucediese. En segundo lugar, la evitabilidad del resultado, o mejor dicho la evitación del resultado, es lo que pretende conseguir el sujeto que desiste de una actuación imprudente que en algún momento, antes de que se produzca la consumación, pasa a ser consciente de la producción efectiva de un resultado lesivo y contrarresta su descuido con actuaciones de control del peligro evitando la lesión del bien jurídico. Es decir, que el sujeto que actúa en ámbitos en los que existen riesgos puede evitar la producción del resultado a través de la no infracción de las normas de cuidado o, una vez que las infringe, porque tome medidas posteriores que logren evitar la producción del hecho lesivo. Sin embargo, la utilización del criterio o idea de la evitabilidad no puede definir la autoría ni en los delitos dolosos ni en los delitos imprudentes, porque el poder de evitar, de interrumpir la producción del hecho, no sólo la tiene el autor, sino cualquier otra persona que "vea" el peligro y lo contrarreste; por otro lado, en el caso de los delitos imprudentes no se puede mantener que "autor de un menoscabo evitable al bien jurídico sólo puede ser quien habría podido controlar su conducta de tal modo que no se hubiera producido el menoscabo al bien jurídico" (MAURACH, Gössel y ZiPf. AT 2, 6. e ed., cit., p. 213. Sobre la posición de estos autores y el concepto de dominio potencial cfr. LuZón PeÑA, en $A D P C P 1989$, pp. 895 y 896 y n. 25; extensamente Roso. Autoría, cit., pp. 135 y ss.), puesto que 
de que hay autoría mediata, lo que directamente incide en sus argumentos para examinar el fin de protección de la norma. Así, mantiene que M no sólo crea un riesgo de lesionar por un atropello realizado por él, sino que también origina el riesgo de que se creen situaciones de pánico guiadas por la idea de huir del lugar, puesto que persiguen obsesivamente, debido al instinto de conservación, la seguridad y la salvación, lo que las convierte en carreras ciegas e instrumentalizadas. Ambos riesgos entrarían dentro del ámbito de protección de la norma.

Trasplantando este esquema argumentativo a la segunda sentencia del auto-stop, considero que se puede llegar a solucionar el caso haciendo responsable a JOAQuín de las lesiones que se produce Iván. A ello se llega teniendo en cuenta la existencia previa de autoría mediata en el examen de la norma y, por tanto, considero que ésta (scil.: la norma) pretende evitar el recurso por parte de la víctima a las autopuestas en peligro y a las autolesiones, que tienen su origen en coacciones, que están dotadas de la suficiente entidad para que, en el caso concreto, sean capaces de configurar una autoría mediata. Estos casos también están incluidos en el fin de protección de la norma. Por tanto, el conductor no sólo crea el riesgo de lesionar la propiedad, la integridad física y la libertad ambulatoria, sino también el riesgo de una autolesión, al intentar la víctima escapar de la situación tirándose del coche, como antes ya he demostrado, pero el fin de protección de la norma sólo tendrá en cuenta este último riesgo y, por tanto, entrará dentro de su ámbito de protección el bien jurídico lesionado de esa concreta manera, si la coacción ha sido suficiente para instrumentalizar a la víctima, y ello obliga a analizar previamente la autoría mediata.

como ya he apuntado antes, ello alude al comportamiento infractor de la norma de cuidado, que como se sabe, es elemento constitutivo y definitorio de la imprudencia (cfr. en este sentido, DíaZ y García Conlledo. Autoría, cit., pp. 599 y 600, en donde expone que la evitabilidad no es más que un "requisito general de la imprudencia"). En conclusión, hay que darle la razón a SiLva de que el sujeto que atropella y genera una situación de pánico y caos, claro que no puede dominar ya la situación, pero al igual que el sujeto que dispara dolosamente una bala y que irremediablemente termina alcanzando a la víctima, puesto que no pudo parar el curso de la bala cuando cambió de opinión y ya no quería matar; es decir que la acción que realiza el sujeto contiene desde el principio una serie de riesgos que hacen que conformen el curso causal forzosamente de una manera y termine con la realización de un resultado concreto. El sujeto domina el hecho desde el momento que decide realizar esa acción y no otra; después sólo hay que dejarla que despliegue todo su potencial lesivo. 
